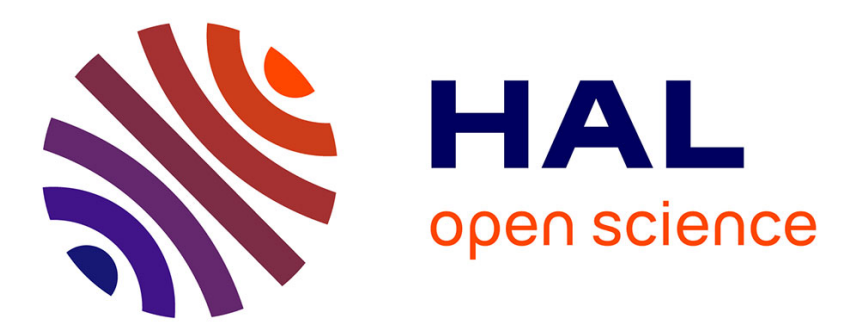

\title{
Response of climate to regional emissions of ozone precursors: sensitivities and warming potentials
}

T. K Berntsen, J. S Fuglestvedt, M. M Joshi, K. P Shine, N. Stuber, M. Ponater, R. Sausen, D. A Hauglustaine, L. Li

\section{- To cite this version:}

T. K Berntsen, J. S Fuglestvedt, M. M Joshi, K. P Shine, N. Stuber, et al.. Response of climate to regional emissions of ozone precursors: sensitivities and warming potentials. Tellus B - Chemical and Physical Meteorology, 2005, 57 (4), pp.283 - 304. 10.3402/tellusb.v57i4.16549 . hal-03324251

\section{HAL Id: hal-03324251 \\ https://hal.science/hal-03324251}

Submitted on 23 Aug 2021

HAL is a multi-disciplinary open access archive for the deposit and dissemination of scientific research documents, whether they are published or not. The documents may come from teaching and research institutions in France or abroad, or from public or private research centers.
L'archive ouverte pluridisciplinaire $\mathbf{H A L}$, est destinée au dépôt et à la diffusion de documents scientifiques de niveau recherche, publiés ou non, émanant des établissements d'enseignement et de recherche français ou étrangers, des laboratoires publics ou privés. 


\section{Response of climate to regional emissions of ozone precursors: sensitivities and warming potentials}

T. K. Berntsen, J. S. Fuglestvedt, M. M. Joshi, K. P. Shine, N. Stuber, M. Ponater, R. Sausen, D. A. Hauglustaine \& L. Li

To cite this article: T. K. Berntsen, J. S. Fuglestvedt, M. M. Joshi, K. P. Shine, N. Stuber, M. Ponater, R. Sausen, D. A. Hauglustaine \& L. Li (2005) Response of climate to regional emissions of ozone precursors: sensitivities and warming potentials, Tellus B: Chemical and Physical Meteorology, 57:4, 283-304, DOI: 10.3402/tellusb.v57i4.16549

To link to this article: https://doi.org/10.3402/tellusb.v57i4.16549 (c) 2005 The Author(s). Published by Taylor \&
Francis.

曲 Published online: 18 Jan 2017.

Submit your article to this journal

III Article views: 138

Q View related articles $\square$

Citing articles: 11 View citing articles $\asymp$ 


\title{
Response of climate to regional emissions of ozone precursors: sensitivities and warming potentials
}

\author{
By T. K. BERNTSEN ${ }^{1}$, J. S. FUGLESTVEDT ${ }^{1}$, M. M. JOSHI ${ }^{2} \dagger$, K. P. SHINE ${ }^{2}, \mathrm{~N}$. \\ STUBER ${ }^{3} \ddagger$, M. PONATER ${ }^{3}$, R. SAUSEN ${ }^{3}$, D. A. HAUGLUSTAINE ${ }^{4}$ and L. Li ${ }^{5}$, \\ ${ }^{1}$ CICERO_Center for International Climate and Environmental Research, Oslo, Norway; ${ }^{2}$ Department of \\ Meteorology, University of Reading, UK; ${ }^{3}$ DLR_Institut für Physik der Atmosphäre, Oberpfaffenhofen, Germany; \\ ${ }^{4}$ Laboratoire des Sciences du Climat et de l'Environnement (LSCE), Gif-sur-Yvette, France; ${ }^{5}$ Laboratoire de \\ Météorologie Dynamique (LMD), Université de Paris 6, Paris, France
}

(Manuscript received 25 June 2004; in final form 11 March 2005)

\begin{abstract}
The response of climate to ozone perturbations caused by regional emissions of NOx or CO has been studied through a sequence of model simulations. Changes in $\mathrm{O}_{3}$ and $\mathrm{OH}$ concentrations due to emission perturbations in Europe and southeast Asia have been calculated with two global 3-D chemical tracer models(CTMs; LMDzINCA and Oslo-CTM2). The radiative transfer codes of three general circulation models (GCMs; ECHAM4, UREAD and LMD) have been used to calculate the radiative forcing of the $\mathrm{O}_{3}$ perturbations, and for a subset of the cases full GCM simulations have been performed with ECHAM4 and UREAD. The results have been aggregated to a global number in two ways: first, through integrating the global-mean radiative forcing of a sustained step change in emissions, and second through a modified concept (SGWP ${ }^{*}$ ) which includes possible differences in the climate sensitivity of $\mathrm{O}_{3}, \mathrm{CH}_{4}$ and $\mathrm{CO}_{2}$ changes. In terms of change in global tropospheric $\mathrm{O}_{3}$ burden the two CTMs differ by less than 30\%. Both CTMs show a higher north/south gradient in the sensitivity to changes in NOx emission than for $\mathrm{CO}$. We are not able to conclude whether real $\mathrm{O}_{3}$ perturbations in general have a different climate sensitivity from $\mathrm{CO}_{2}$. However, in both GCMs high-latitude emission perturbations lead to climate perturbations with higher (10-30\%) climate sensitivities. The calculated SGWP*, for a $100 \mathrm{yr}$ time horizon, are negative for three of the four CTM/GCM combinations for European emissions ( -9.6 to +6.9$)$, while for the Asian emissions the $\mathrm{SGWP}^{*}(H=100)$ is always positive $(+2.9$ to +25$)$ indicating a warming. For CO the SGWP $^{*}$ values (3.8 and 4.4 for European and Asian emissions respectively, with only the Oslo-CTM2/ECHAM4 model combination) are less regionally dependent. Our results support the view that for NOx, regionally different weighting factors for the emissions are necessary. For CO the results are more robust and one global number may be acceptable.
\end{abstract}

\section{Introduction}

According to the principle of comprehensiveness embedded in the UN Framework Convention on Climate Change (Article 3.3), policies and measures to mitigate human-induced climate change should "cover all relevant sources, sinks and reservoirs of greenhouse gases". The Kyoto Protocol of 1997 regulates emissions of carbon dioxide $\left(\mathrm{CO}_{2}\right)$, methane $\left(\mathrm{CH}_{4}\right)$, nitrous oxide $\left(\mathrm{N}_{2} \mathrm{O}\right)$, perfluorocarbons (PFC), sulfur hexafluoride $\left(\mathrm{SF}_{6}\right)$ and hydrofluorocarbons (HFC). However, there are several other source gases that are likely to make a significant indirect contribution to an-

\footnotetext{
*Corresponding author.

e-mail: t.k.berntsen@ cicero.uio.no

$\dagger$ Current affiliation: The Met Office, Exeter, UK.

$\ddagger$ Current affiliation: Department of Meteorology, University of Reading, UK.
}

thropogenic radiative forcing of climate by affecting the concentrations of other climate forcing agents through complex chemical processes in the atmosphere. Tropospheric ozone $\left(\mathrm{O}_{3}\right)$ is important in this context; it is believed to have caused a radiative forcing since pre-industrial times of a similar size to that of methane (e.g. IPCC, 2001). The magnitude of this forcing is uncertain because inadequate observations of the change in ozone concentrations necessitate the use of numerical models to simulate that change. Furthermore, changes in chemical processes and the concentrations of $\mathrm{OH}$, the main oxidizing agent in the troposphere, are likely to have led to changed lifetimes and concentrations of various Kyoto gases such as $\mathrm{CH}_{4}$ and HFCs (Crutzen, 1987; Fuglestvedt et al., 1996).

The gases currently regulated by the 1997 Kyoto Protocol are long-lived so that they are relatively well-mixed in the troposphere and the concentrations are largely independent of the location of the emissions. By contrast, the impact on climate 
of short-lived gases could be very sensitive to the geographical location of their emissions, as the resulting changes in concentration are inhomogeneous. For some short-lived species like HFC the response of climate to emissions is linear but dependent on the location of the emissions, while for ozone precursors the situation is more complicated. First, the magnitude of ozone and $\mathrm{OH}$ perturbations caused by emissions of the short-lived species depends on the physical and chemical background (in particular the NOx level) in a non-linear way (Isaksen et al., 1978; Lin et al., 1988; Fuglestvedt et al., 1999; Berntsen et al., 2005). Second, the radiative forcing from changes in ozone depends on where these changes occur. It is well-established that changes in upper tropospheric ozone concentrations lead to a larger radiative forcing (e.g. Wang and Sze, 1980; Lacis et al., 1990) than changes nearer the surface; and changes in ozone in the tropics and subtropics have a considerably larger (up to a factor of 2) impact on radiative forcing than changes at high latitudes (e.g. Berntsen et al., 1997). Third, there is the possibility that the climate sensitivity parameter, $\lambda$, which relates globally averaged radiative forcing (RF) to global-mean temperature change at equilibrium $\left(\Delta T_{\text {eq }}=\right.$ $\lambda \mathrm{RF}$ ), could be different from its value for homogeneous carbon dioxide changes for certain climate change mechanisms, such as changes in tropospheric ozone (Hansen et al., 1997; Sausen et al., 2002; Joshi et al., 2003; Mickley et al., 2004). In addition, the inhomogeneity in the forcing can be expected to lead to some inhomogeneity in climate response, relative to that for carbon dioxide changes; it is possible that the wider societal impacts of such inhomogeneous temperature changes would differ from those due to the same global-mean radiative forcing due to $\mathrm{CO}_{2}$ changes.

Given the likely significant contribution from tropospheric ozone to radiative forcing since pre-industrial times (IPCC, 2001), the "comprehensiveness", and thus potentially the costeffectiveness, of the future revisions of the Kyoto Protocol could be enhanced by inclusion of short-lived gases with indirect effects. However, expansion of the comprehensive approach to include emissions of short-lived gases with inhomogeneous effects that vary depending on location may be difficult due to complex processes and large uncertainties. To do this on a scientifically sound basis, within the current operational basis of the comprehensive approach based on global warming potentials (GWPs) for conversion to ' $\mathrm{CO}_{2}$ equivalents', would most likely require that, for example, NOx emissions were given geographically varying GWP values (e.g. Johnson and Derwent, 1996; Derwent et al., 2001; Wild et al., 2001). These GWP values will to a large degree depend on calculations with chemical tracer models (CTMs) and radiative transfer models (RTMs). To make the inclusion of short-lived climate gases feasible in the further development of climate policies requires scientific credibility of the derived RF and GWPs which again means that the results should not be too model dependent. In principle, since the effects on $\mathrm{OH}$ and $\mathrm{O}_{3}$ depend on the time and location of emissions, the GWPs should be given with a resolution that takes this into account. But there is a trade-off between political feasibility and scientific accuracy, and to avoid making this too complicated the GWPs must be given as global or regional as well as yearly or seasonal averages.

In this paper we investigate the impact of $\mathrm{NOx}$ and $\mathrm{CO}$ emissions in two different regions of the world (southeast Asia and Europe) on tropospheric ozone, oxidation capacity and radiative forcing and spatial temperature response. We use two global 3-D CTMs and three general circulation models (GCMs) which enable us to explore the degree of model dependency related to these questions. We discuss the different responses to changes in emissions in terms of concentrations and lifetimes, radiative forcing, the climate sensitivity parameter and the different spatial patterns of temperature changes. Finally, we use the combined results, including the information about differences in the climate sensitivity of regional radiative forcings, to derive emission indices (i.e. $\mathrm{CO}_{2}$ equivalent emissions) for $\mathrm{NOx}$ and $\mathrm{CO}$ emissions from Asia and Europe based on a modified GWP concept.

\section{Experimental design}

It has been common to use RF as a metric for comparing different contributions to climate change. This is implicitly making the assumption that although the value of the climate sensitivity parameter, $\lambda$, is poorly known it is independent of the particular mechanism causing that RF. This assumption carries over to the use of GWPs for comparing different emissions. However, several recent papers (e.g. Hansen et al., 1997; Christiansen, 1999; Forster et al., 2000; Rotstayn and Penner, 2001; Stuber et al., 2001; Joshi et al., 2003) have brought this key hypothesis under increasing scrutiny.

In order to select an appropriate set of numerical experiments for this study we have been guided by two main ideas. First, the regional perturbations of the climate system should have a more realistic character than the largely idealized patterns used in previous papers on global climate response to a spatially inhomogeneous forcing (e.g. Hansen et al., 1997; Christiansen, 1999; Joshi et al., 2003). Ozone is the major gas-phase forcing agent with a short enough lifetime to cause a significantly inhomogeneous distribution of radiative forcing, and has thus been chosen as the key forcing agent for this study. Second, as both the patterns of change of ozone concentration due to the emission of short-lived precursors (e.g. Jacob et al., 1997; Gauss et al., 2003) and the response of temperature to inhomogeneous changes in ozone (Joshi et al., 2003) are severely model dependent at this stage, we felt that a variety of models ought to be employed in order to yield a reasonable impression of the current range of uncertainty.

Four basic cases of emission perturbation were chosen to form the input for the models involved: regional enhancement of emissions of NOx or CO for either Europe or southeast Asia. Table 1 gives the area of the perturbations and the magnitude of the emission perturbations. In the CTMs the emission perturbation 
Table 1. Description of emission perturbations used in the CTMs

\begin{tabular}{lcc}
\hline Perturbation & \multicolumn{1}{c}{ Region } & Emission (fossil fuels) \\
\hline CO-Europe & Europe $\left(40^{\circ}-60^{\circ} \mathrm{N}, 10^{\circ} \mathrm{W}-20^{\circ} \mathrm{E}\right)$ & $+40 \mathrm{Tg} \mathrm{yr}^{-1}$ of CO \\
CO-Asia & SE Asia $\left(10^{\circ}-30^{\circ} \mathrm{N}, 100^{\circ}-120^{\circ} \mathrm{E}\right.$ & $+40 \mathrm{Tg} \mathrm{yr}^{-1}$ of CO \\
NOx-Europe & Europe $\left(40^{\circ}-60^{\circ} \mathrm{N}, 10^{\circ} \mathrm{W}-20^{\circ} \mathrm{E}\right)$ & $+1 \mathrm{Tg}(\mathrm{N}) \mathrm{yr}^{-1}$ of NOx \\
NOx-Asia & SE Asia $\left(10^{\circ}-30^{\circ} \mathrm{N}, 100^{\circ}-120^{\circ} \mathrm{E}\right.$ & $+1 \mathrm{Tg}(\mathrm{N}) \mathrm{yr}^{-1}$ of NOx \\
\hline
\end{tabular}

(e.g. $+1 \mathrm{Tg}(\mathrm{N}) \mathrm{yr}^{-1}$ of NOx) was defined by enhancing the emissions from fossil fuel combustion only by the same factor across the whole region. The emissions used for the reference case are equal in the two CTMs and described in Section 3.

The inclusion of both NOx and CO is motivated by the distinctive chemistry-climate impact these two precursors create through their respective feedbacks on ozone on the one hand and on methane on the other. The key regions of Europe and southeast Asia have been chosen to represent both an extratropical and a tropical perturbation, which offers the possibility to check if the findings of Joshi et al. (2003) with respect to different climate sensitivities for different latitudinal regimes can be reproduced for more realistic perturbations.

Two different CTMs (to be described in the next section) have been used to calculate distributions of change in ozone and changes in methane lifetime for each of the four emission scenarios. The resulting ozone perturbations were then transferred to three different GCMs (also described later, in Section 3) in order to calculate the radiative transfer, yielding first a sample of six RF realizations for each of the basic emission scenarios. The RF due to methane changes, caused by changing the oxidation capacity of the atmosphere, could be calculated in a simpler way ( $c f$. Sections 4 and 5). However, the equilibrium climate change experiments designed to determine the response of climate and the climate sensitivity parameter could not be performed for all GCMs for each scenario due to the excessive computer resources required for this task. A subsample of seven cases (six patterns of ozone change plus a homogeneous increase in methane concentration) was selected instead and will be described in detail in Section 6. In most cases more than one GCM was used to retain an impression of possible model uncertainties. Equilibrium climate change experiments require a certain magnitude of forcing as the signal to noise ratio must be large enough to detect a statistically significant response of, say, the distribution of surface air temperature. This magnitude is not reached by the ozone perturbations delivered from the CTMs, which all are characterized by $\mathrm{RFs}$ lower than $0.01 \mathrm{~W} \mathrm{~m}^{-2}$. Hence, each of the forcings selected for the climate simulations have been scaled to a global-mean RF value of about $1 \mathrm{~W} \mathrm{~m}^{-2}$, first to avoid the statistical problems just mentioned and second to ensure a maximum of comparability with respect to the resulting climate sensitivity values. This kind of approach has been successfully established in previous papers (Hansen et al., 1997; Stuber et al., 2001; Joshi et al., 2003).
In a last step, the various results of radiative forcing and climate sensitivity (including the intermodel variability) have been used to calculate a modified GWP for NOx and CO emissions in Europe and Asia. These calculations will be described in detail in Section 7.

\section{Model description}

\subsection{Chemical transport models}

LMDz (version 3.3) is a GCM developed initially for climate studies (Sadourny and Laval, 1984). The model has been adapted in order to simulate the transport of trace species and is coupled on-line to the chemistry-aerosols model INCA (INteraction with Chemistry and Aerosols). The present version of the model has 19 hybrid levels from the surface to $3 \mathrm{hPa}$ and a horizontal resolution of $2.5^{\circ}$ in latitude and $3.75^{\circ}$ in longitude. The largescale advection of tracers is performed using a finite-volume transport scheme Van Leer (1977) as described in Hourdin and Armengaud (1999). Convective transport is simulated using a mass flux scheme (Tiedtke, 1989). The planetary boundary layer scheme is based on a second-order closure approximation. The current version of the model uses a $\mathrm{CH}_{4}-\mathrm{NO}_{x}-\mathrm{CO}-\mathrm{O}_{3}$ chemical scheme representative of the background chemistry of the atmosphere and including 19 photochemical reactions and 66 chemical reactions. INCA calculates on-line the time evolution of 33 chemical species and tracers with a time step of $30 \mathrm{~min}$. In the present version of the model, the feedback of the chemistry on the radiation is not taken into account. A zonal and monthly ozone climatology is prescribed above the tropopause based on $\mathrm{Li}$ and Shine (1995). An interactive lightning NOx emission scheme is used in the model (Jourdain and Hauglustaine, 2001). While the LMDz GCM wind fields can be relaxed towards the European Centre for Medium Range Weather Forecasting (ECMWF) reanalysis, this model feature is not activated in the version of LMDz used in this study and the GCM winds fields, temperature, humidity and cloudiness are used to drive the transport and chemistry of the chemical species. A detailed description and evaluation of the model is provided by Hauglustaine et al. (2004).

The University of Oslo CTM2 model (hereafter denoted by $\mathrm{UiO})$ is an off-line chemical transport model that uses precalculated meteorological fields to drive the chemical turnover and distribution of tracers in the troposphere (Sundet, 1997; 
Kraabøl et al., 2002). The resolution is T21 $\left(5.6^{\circ} \times 5.6^{\circ}\right)$ in the horizontal and 19 levels from the surface up to $10 \mathrm{hPa}$ in the vertical. The meteorological input data have been generated for the year 1996, by running the Integrated Forecast System (IFS) model at ECMWF in a series of $36 \mathrm{~h}$ forecasts starting from the analysed fields every $24 \mathrm{~h}$. Linking together the last $24 \mathrm{~h}$ of the forecasts gives us a continuous record of input data. The advection of chemical species is calculated by the second-order moment method (Prather, 1996). Vertical mixing by convection is based on the Tiedtke mass flux scheme (Tiedtke, 1989). Turbulent mixing in the boundary layer is treated according to the Holtslag K-profile scheme (Holtslag et al., 1990). The chemical scheme includes 62 chemical compounds and 130 gas-phase reactions in order to describe the photochemistry of the troposphere (Berntsen and Isaksen, 1997, 1999). The scheme is solved using the quasi-steady-state approximation (Hesstvedt et al., 1978). Photodissociation rates are calculated on-line, following the approach described in Wild et al. (2000). NOx emissions from lightning are coupled on-line to the convection in the model using the parametrization proposed by Price and Rind (1993) and the procedure given by Berntsen and Isaksen (1999).

The reference simulation for both models (UiO and LMDzINCA) is defined based on the IPCC (2001) OXCOMP intercomparison exercise (Prather et al., 2003; Gauss et al., 2003). The CO and NOx emission strengths are prescribed according to OXCOMP, except for biomass burning emissions which are specific to each model. The version of LMDzINCA used in this study does not include an explicit scheme for degradation of non-methane hydrocarbons (NMHC). Therefore, secondary CO emissions are introduced in the model based on the estimates in Chapter 4 of IPCC (2001). Replacing the NMHCs by additional $\mathrm{CO}$ emissions leads to reduced production of peroxy radicals, and thus lower ozone production. Lightning NOx emissions are constrained to $5 \mathrm{Tg}(\mathrm{N})$ in both models. All the chemistry simulations are run for 18 months including a 6 month spin-up.

\subsection{General circulation models}

The two GCMs used for the radiative forcing calculations as well as for the equilibrium climate change simulations are identical to those used in Joshi et al. (2003), thus a brief description is sufficient here. The models are designated as ECHAM4 and UREAD throughout this paper, the first being a sophisticated GCM while UREAD represents a so-called intermediate GCM with less sophisticated physics and hence a lower computational demand. UREAD has the largest vertical domain, reaching up to $1 \mathrm{hPa}$ with 19 layers in the vertical. ECHAM4 has the same number of layers but has its highest full level at $10 \mathrm{hPa}$. ECHAM4 has a horizontal resolution of spectral T30 (approximately $4^{\circ}$ ) and UREAD is spectral T21 (approximately $6^{\circ}$ ) latitude. Both GCMs include a module describing changes of the oceanic mixed-layer temperature, using prescribed heat fluxes derived from a control run, and both include a module describing the sea ice cover. All models, including the LMD GCM (see also Joshi et al., 2003) are capable of calculating the stratosphere-adjusted RF according to the fixed dynamical heating approximation. The radiation code from the LMD GCM is used in the calculations of the radiative forcing presented in Section 5; the calculations are performed on a $7.2^{\circ} \times 10^{\circ}$ horizontal grid and 19 levels in the vertical, with an upper level at $10 \mathrm{hPa}$. However, we do not use climate change results from the LMD GCM here, because it was shown by Joshi et al. (2003) that simplifications in the representation of sea ice in that model led to an unrealistic sea-ice albedo feedback which make this model less suitable for studying the impact of regional differences in forcing, which are the focus of this paper. As for those GCMs used for the equilibrium climate change simulations, there is a factor of 2 difference in the climate sensitivity to changes in $\mathrm{CO}_{2}$ between the two models and hence any robust features emerging from a comparison with these models might be expected to be present in GCMs more generally.

\section{Impact on chemical composition}

Enhancing the emissions of either NOx or CO in Europe or southeast Asia does in general enhance ozone concentrations by increasing the photochemical production of ozone. However, the efficiency of the ozone enhancement does vary significantly by both region and season depending non-linearly on the background levels of primarily NOx (the catalyst in the ozone production) but also on CO, VOCs, sunlight, etc. (e.g. Crutzen, 1987; Lin et al., 1988; Berntsen et al., 2005).

Figure 1 shows the zonally and annually averaged perturbations of ozone for the four emission perturbations used in the two CTMs ( $c f$. Table 1).

Increasing the $\mathrm{CO}$ emissions by $40 \mathrm{Tg} \mathrm{yr}^{-1}$ in either Europe or southeast Asia leads in both CTMs to enhancements of ozone by $0.2-0.4$ ppbv (parts per billion by volume) in the upper troposphere/lower stratosphere (UT/LS) region in the Northern Hemisphere (upper panels in Fig. 1). The magnitude of the ozone perturbations decreases closer to the surface in both CTMs. Although the $\mathrm{CO}$ perturbation itself decreases with altitude, the higher NOx concentrations in the UT/LS region enhances the ozone production compared with the middle free troposphere. Further down, in the planetary boundary layer (PBL), the higher background NOx concentrations enhance ozone production (by the CO perturbation). However, the lifetime of ozone in the PBL is much shorter than in the free troposphere due to more rapid chemical loss and dry deposition of ozone at the surface, thus limiting the ozone enhancement. The vertical gradient in the ozone perturbation is more pronounced in $\mathrm{UiO}$ than in the LMDzINCA model. This is due to more efficient vertical mixing in the LMDzINCA model (Rogers et al., 2002; Berntsen et al., 2003; Hauglustaine et al., 2004). However, due to the limited observational data available that can be used to verify vertical mixing in CTMs, it is not possible to decide which of the models is most realistic in terms of vertical mixing. 
LMDzINCA, CO-Europe

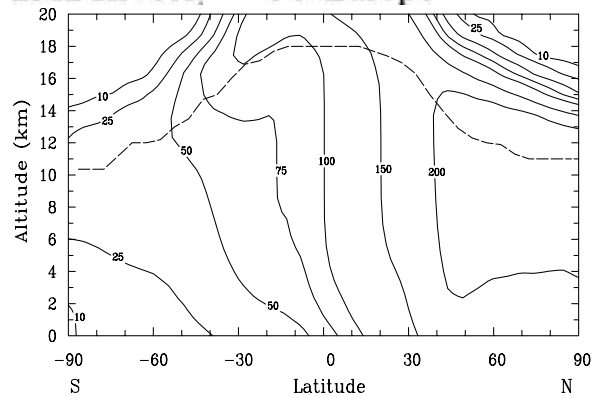

LMDzINCA, CO-Asia

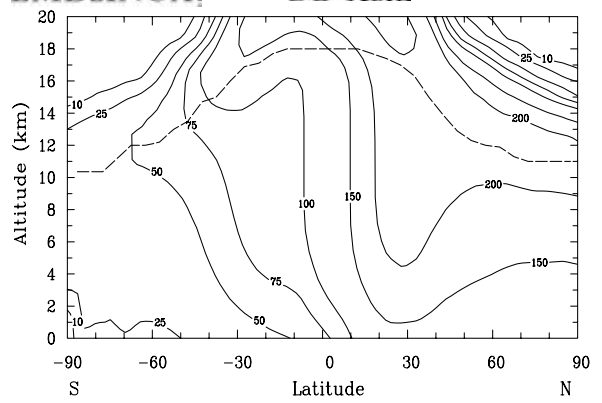

LMDzINCA: NOx-Europe

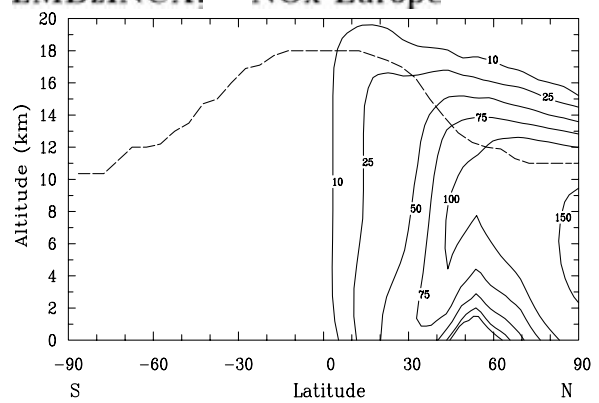

LMDzINCA, NOx-Asia

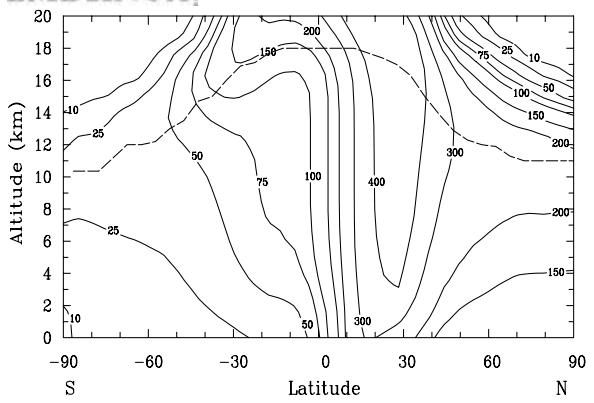

UiO, CO-Europe

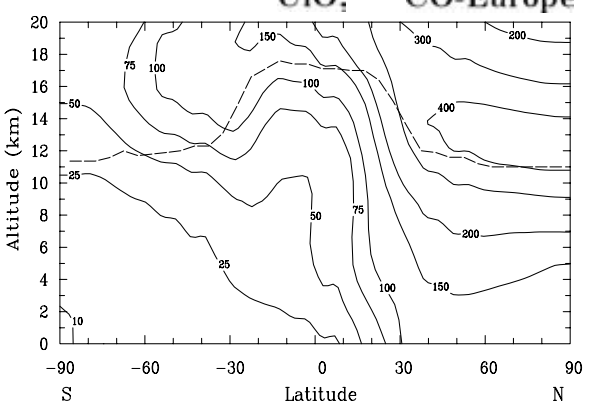

UiO, CO-Asia

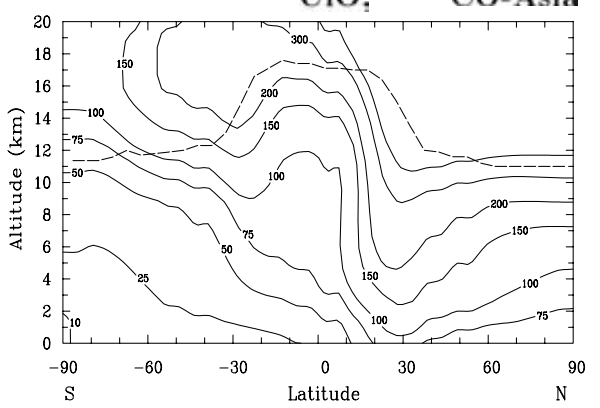

UiO, NOx-Europe

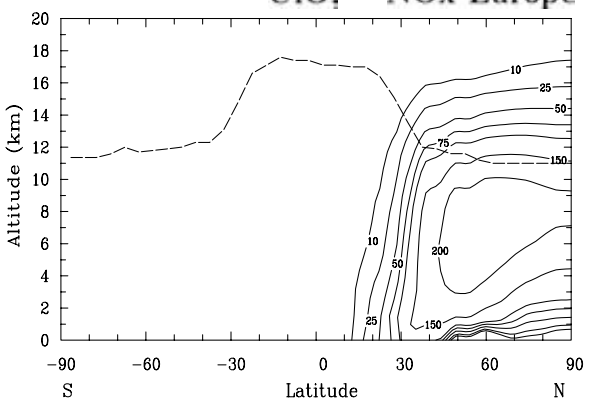

UiO, NOx-Asia

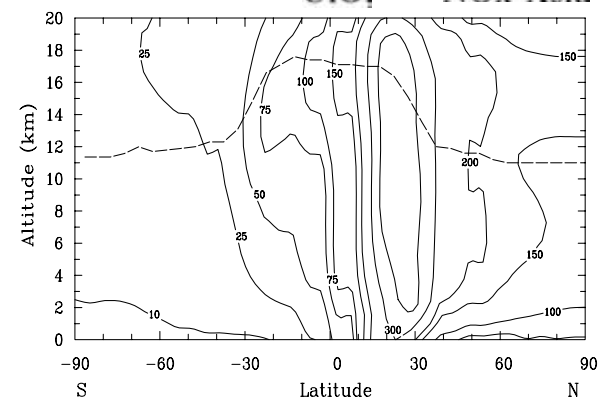

Fig. 1. Zonal and annual change in ozone mixing ratios (pptv) from the four emission perturbations defined in Table 1. Dashed lines show the 200 ppbv background ozone levels.

Since neither of the CTMs includes stratospheric chemistry, the ozone concentrations in the stratosphere are treated as an upper boundary condition. In the UiO model ozone concentrations are fixed at the upper boundary $(10 \mathrm{hPa})$, while in LMDzINCA ozone is prescribed closer to the tropopause (potential temperature of $380 \mathrm{~K}$ ). This difference explains why the ozone perturbations (in particular for the low-latitude experi- ments) extend to higher altitudes in the lower stratosphere in the UiO model. Although this appears to be a major difference (e.g. in the CO-Asia case) it has been shown that the same absolute ozone perturbation in and above the mid-stratosphere has a significantly smaller effect on radiative forcing compared with changes in the vicinity of the tropopause (e.g. Lacis et al., 1990). 


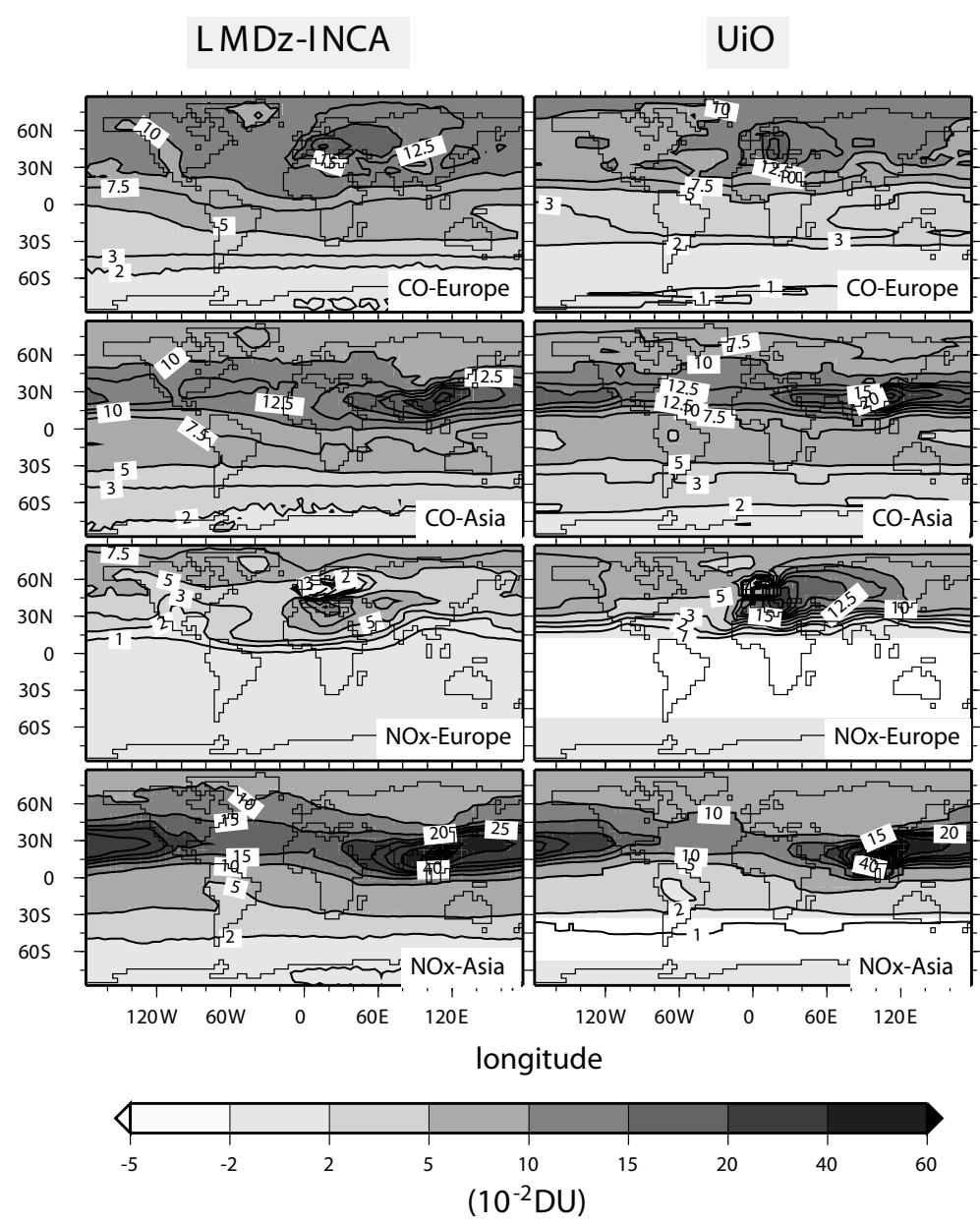

Fig. 2. Annual averaged changes in the tropospheric ozone column $\left(10^{-2} \mathrm{DU}\right)$. Levels where the annual averaged ozone concentrations are above $200 \mathrm{ppbv}$ are defined as stratospheric.
The responses in ozone to the perturbations in NOx emissions are of the same magnitude as for the $\mathrm{CO}$ perturbations, but as expected the differences between the two regions are more pronounced in the NOx cases due to the shorter lifetime of NOx (lower panels in Fig. 1). In the NOx-Europe case both models show the largest ozone perturbations in the middle free troposphere $\left(4-10 \mathrm{~km}\right.$, and pole-ward of about $\left.40^{\circ} \mathrm{N}\right)$. In the PBL over Europe adding NOx to the already high NOx concentrations leads to a reduction in ozone in both models (see Fig. 2). In the NOx-Asia case, the active convection in this region deposits NOx in the UT/LS region. Both CTMs calculate a dipole pattern in the NOx perturbations during spring, summer and autumn. In July NOx increases by more than 10 pptv (parts per trillion by volume) in the UT/LS region in both models, while at $5 \mathrm{~km}$ altitude the increases are only 0-2 pptv. Nevertheless, the ozone perturbation is more or less homogeneous in the vertical above the PBL. Again, this can be explained by more efficient ozone production at $5 \mathrm{~km}$ due to the low background NOx levels, and the longer lifetime of ozone which allows for more vertical mixing.
Due to relatively short lifetimes of the ozone precursors (in particular NOx, which has a lifetime of generally less than $24 \mathrm{~h}$ in the PBL) and also for ozone itself, there are significant gradients in the ozone perturbations in the longitudinal direction as well. Figure 2 shows the annual averaged change in the tropospheric ozone column for the eight simulations. Due to the differences in upper boundary formulation in the CTMs noted above, changes in ozone at altitudes where the annual mean background ozone level exceeds 200 ppbv are defined as stratospheric and are neglected here.

For the $\mathrm{CO}$ experiments, there are small differences between the two CTMs, both calculating a stronger increase $(+30-50 \%)$ in the ozone column for the CO-Asia case compared with the COEurope case. In the CO-Asia case the increase is slightly higher and more localized over the source areas in the UiO model. As could be expected, the regional gradients become more pronounced for the NOx cases. For the NOx-Europe case both CTMs show a dipole structure in the column change with maximum increase over southeast Europe and reduced ozone columns over northwest Europe. The reduction is due to the reaction of the 
source gas NO with ozone, and reduced ozone production of other NOx sources in this region with high background NOx levels when additional NOx is added. The maximum increase is significantly higher in UiO than in LMDzINCA ( 0.25 versus 0.10 Dobson units (DU)). In the UiO model the plume of the elevated ozone column stretches across the Eurasian continent and as far as Alaska, while this plume is much less pronounced in LMDzINCA, reaching only about $110^{\circ} \mathrm{E}$. A second, but less pronounced, plume is visible in both models extending southwestwards to the central North Atlantic. By far the largest perturbations in the local ozone columns are found for the NOx-Asia case. Compared with the NOx-Europe case, the lower background NOx levels and more available sunlight give larger ozone production, while the chemical lifetimes of both precursors and ozone cause steeper horizontal gradients. The longer lifetime of CO compared with NOx leads to more widespread ozone changes with shallower horizontal gradients in the $\mathrm{CO}$ Asia case. Again the maximum in the $\mathrm{UiO}$ model is higher than in the LMDzINCA model (1.5 and 0.75 DU respectively). Both models predict plumes extending eastwards across the Pacific at $20-40^{\circ} \mathrm{N}$, and westwards towards eastern Africa at $10-30^{\circ} \mathrm{N}$. At about $30^{\circ}(3000 \mathrm{~km})$ downstream from the maximum, the column change is equal in the two CTMs, and further away from the source the perturbation is larger in the LMDzINCA model. This is in agreement with the results of Hauglustaine et al. (2004) indicating an efficient large-scale transport and mixing simulated by the LMDz model.

The reason for the generally steeper gradients in the $\mathrm{UiO}$ model is probably a combination of chemistry, meteorological input data, differences in the numerical advection schemes and mixing (convection, boundary layer). Differences in the tracer transport (meteorological input data and numerical advection schemes) can be identified as the main cause since plots of the column CO change in the CO-Asia case show a very similar pattern to the column ozone change in the NOx-Asia case. Due to its relatively long lifetime compared with characteristic transport times out of the source regions, the $\mathrm{CO}$ perturbations in the CO-Asia case can be viewed almost as an inert tracer experiment. Also, there are no indications of significant differences in the loss of CO (by comparing the methane lifetimes, see next section). The inclusion of NMHC chemistry in the UiO model could contribute to the steeper ozone gradient in this model, since short-lived hydrocarbons that are a major source of peroxy radicals, which together with $\mathrm{NOx}$ drive ozone production in the source region. Compensating for the missing NMHCs in LMDzINCA by adding an extra CO source leads to more widespread ozone production. Working in the other direction, the higher horizontal resolution of the LMDzINCA model should enhance the ability of this model to keep steep gradients compared with the UiO model. Also, the generally higher background NOx concentrations in the PBL in the UiO model should make the ozone production efficiency of additional NOx lower due to non-linear chemical effects (e.g. Lin et al., 1988).
Table 2. Calculated increase in tropospheric ozone mass ( $\mathrm{Tg}$ ) below levels with background ozone concentrations less than $200 \mathrm{ppbv}$ for the two CTMs

\begin{tabular}{lcc}
\hline & $\mathrm{UiO}, \Delta \mathrm{O}_{3}(\mathrm{Tg})$ & LMDzINCA, $\Delta \mathrm{O}_{3}(\mathrm{Tg})$ \\
\hline CO-Europe & 0.59 & 0.78 \\
CO-Asia & 0.83 & 0.84 \\
NOx-Europe & 0.26 & 0.19 \\
NOx-Asia & 0.93 & 1.16 \\
\hline
\end{tabular}

The total changes in tropospheric ozone mass (defined as altitudes below levels with ozone concentrations less than 200 ppbv as in Fig. 2) are given in Table 2. The larger increases in ozone mass in the LMDzINCA model (except in the NOxEurope case) are not caused by larger changes in the regions with maximum increases in the ozone concentrations but by a more widespread change in ozone, also into the Southern Hemisphere. The slightly higher altitude of the background $200 \mathrm{ppbv}$ ozone in LMDzINCA also makes a small contribution.

\subsection{Oxidation capacity}

Changing the emissions of $\mathrm{NOx}$ or $\mathrm{CO}$ also changes the oxidation capacity of the atmosphere through changes in the abundance of the $\mathrm{OH}$ radical. Increasing the $\mathrm{CO}$ emissions leads to less $\mathrm{OH}$, mainly by shifting the balance between the $\mathrm{HOx}\left(=\mathrm{OH}+\mathrm{HO}_{2}\right)$ radicals in favour of $\mathrm{HO}_{2}$ through the oxidation of $\mathrm{CO}$ itself by

$\mathrm{CO}+\mathrm{OH} \rightarrow \mathrm{CO}_{2}+\mathrm{H}$

$\mathrm{H}+\mathrm{O}_{2}+\mathrm{M} \rightarrow \mathrm{HO}_{2}+\mathrm{M}$

The additional primary production of $\mathrm{OH}$ through the enhancement of ozone is not enough to counteract this. In the cases where the NOx emissions have been increased, the $\mathrm{OH}$ levels are increased with the main contributions from two factors (e.g. Poppe et al., 1993): by the enhanced primary production by ozone photolysis, but also through a shift from $\mathrm{HO}_{2}$ to $\mathrm{OH}$ through

$\mathrm{NO}+\mathrm{HO}_{2} \rightarrow \mathrm{NO}_{2}+\mathrm{OH}$

The change in the $\mathrm{OH}$ concentrations causes a change in the loss frequency of methane $(\Delta L)$ (i.e. the weighted global average of the $\mathrm{OH}$ change) which is given by ( $c f$. values in Table 3$)$ :

$\Delta L=-\frac{\Delta \tau_{0}}{\tau_{\mathrm{pert}} \cdot \tau_{\mathrm{ref}}}$

where $\tau_{\text {ref }}$ and $\tau_{\text {pert }}$ are the methane lifetimes in the reference and perturbation simulations respectively, and $\Delta \tau_{0}$ is change in methane lifetime in the perturbation cases $\left(\tau_{\text {pert }}-\tau_{\text {ref }}\right)$. The lifetime of methane with respect to loss by $\mathrm{OH}$ in the reference case is 11.52 and $7.74 \mathrm{yr}$ for the LMDzINCA and UiO models respectively. These values more or less bracket the values given by IPCC (2001) for seven CTMs (6.5-13.8 yr), and the range 
Table 3. Estimated changes in methane loss rate, lifetime and methane concentrations (at steady state) caused by the $\mathrm{CO}$ and NOx emission perturbations

\begin{tabular}{|c|c|c|c|c|c|c|}
\hline \multirow[b]{2}{*}{ Perturbation } & \multicolumn{3}{|c|}{$\mathrm{UiO}$} & \multicolumn{3}{|c|}{ LMDzINCA } \\
\hline & $\begin{array}{c}\Delta L \\
\left(10^{-11} \mathrm{~s}^{-1}\right)\end{array}$ & $\begin{array}{l}\Delta \tau_{0} \\
(\mathrm{yr})\end{array}$ & $\begin{array}{l}\Delta \mathrm{CH} 4 \\
\text { (ppbv) }\end{array}$ & $\begin{array}{c}\Delta L \\
\left(10^{-11} \mathrm{~s}^{-1}\right)\end{array}$ & $\begin{array}{l}\Delta \tau_{0} \\
(\mathrm{yr})\end{array}$ & $\begin{array}{l}\Delta \mathrm{CH} 4 \\
\text { (ppbv) }\end{array}$ \\
\hline CO-Europe & -1.37 & 0.026 & 8.25 & -1.71 & 0.072 & 15.3 \\
\hline CO-Asia & -1.32 & 0.025 & 7.93 & -1.64 & 0.069 & 14.6 \\
\hline NOx-Europe & 0.36 & -0.0068 & -2.22 & 0.33 & -0.014 & -2.97 \\
\hline NOx-Asia & 1.32 & -0.025 & -7.93 & 1.28 & -0.054 & -11.4 \\
\hline
\end{tabular}

given by our two CTMs can thus be regarded as representative for the current model uncertainties. Prinn et al. (2001) estimates the lifetime of methane with respect to loss by $\mathrm{OH}$ to $8.9(-1.1$, +1.4 ) yr, based on observations of concentration and estimates of the emissions of $\mathrm{CH}_{3} \mathrm{CCl}_{3}$.

In the $\mathrm{CO}$ cases the LMDzINCA model gives about a $25 \%$ larger reduction in the loss rate than the $\mathrm{UiO}$ model, probably because of more widespread $\mathrm{CO}$ changes towards lower latitudes in the LMDzINCA model. For the NOx cases the difference between the models are less than $10 \%$. Due to difference between the lifetime of methane in the two models, the difference between the two CTMs in $\Delta \tau_{0}$ is almost a factor 3 for the CO cases.

The changes in $\mathrm{OH}$ concentrations calculated by the relatively short (less than 2 yr) CTM simulations will induce changes in methane with an adjustment time of about $14 \mathrm{yr}$, which is significantly longer than the CTM simulations (Prather, 1996; Wild et al., 2001; Derwent et al., 2001). The methane changes enhance the $\mathrm{OH}$ perturbation through a positive feedback. However, based on the initial changes in methane lifetime (Table 3), the changes in methane concentrations at steady state can be estimated even if the CTM simulations are not run for the long period of time (several decades) required to get to steady state for methane ( $c f$. Fuglestvedt et al., 1999). The estimated changes in methane require the use of a feedback factor (or the ratio between the adjustment time and the lifetime). This feedback factor is model dependent, but since very costly multidecadal simulations in the CTM are needed to calculate it, we do not have these data available from the two CTMs. Instead we have used the feedback factor of 1.4 (IPCC, 2001) for both CTMs to derive the numbers for $\Delta \mathrm{CH}_{4}$ at steady state given in Table 3, using the procedure given in Fuglestvedt et al. (1999):

$\Delta \mathrm{CH}_{4}=1.4 C_{0} \frac{\Delta \tau_{0}}{\tau_{\text {ref }}}$

where $C_{0}$ is the observed current concentration (1745 ppbv) of methane

\section{Radiative forcing}

The stratosphere-adjusted radiative forcing has been calculated for the eight ozone perturbations described in Section 4, using the radiation codes from each of the GCMs as described in Section 3.
The 3-D ozone perturbations were interpolated from the CTM grid to the GCM grid and added to the background ozone of each GCM. Figures 3 and 4 present the resulting geographical distributions for two emission scenarios (NOx-Asia and NOx-Europe, respectively). The details of the spatial structure are mainly reflected by the respective patterns of ozone change. Hence, the RF patterns are evidently quite similar between the different realizations of the same scenario, while there are clear differences between the different scenarios. Not surprisingly, the representation of pattern details becomes less apparent with decreasing GCM horizontal resolution. The RF distributions due to ozone changes arising from regional $\mathrm{CO}$ emissions (not shown) are even more similar, as they are smoother due the longer lifetime of $\mathrm{CO}$ in comparison to NOx (see Section 4). A number of differences in the radiative forcing patterns are clearly caused by differences in the basic ozone perturbation patterns, e.g. the larger gradients along $20^{\circ} \mathrm{N}$ to $30^{\circ} \mathrm{N}$ in the UiO-based RF distributions of the NOx-Europe case or the larger RF maxima at $25^{\circ} \mathrm{N}, 110^{\circ} \mathrm{E}$ showing up in the UiO-based NOx-Asia scenario. Another example is the larger RF values in the Southern Hemisphere extratropics yielded by all GCMs from the LMDzINCA-based NOx-Asia perturbations. Not every feature in the distribution of column ozone perturbations is reflected in the corresponding RF distributions. For example, the negative ozone anomaly over northwestern Europe simulated by the $\mathrm{UiO}$ model is not accompanied by a negative RF anomaly in any of the GCMs, independent of the latter's resolution. Apparently, the negative ozone perturbation in the PBL, as discussed in Section 4, dominates the ozone column but not the net RF, which is more strongly influenced by increasing long-wave RF contributions from the upper troposphere.

Background conditions such as, for example, surface albedo, snow cover and cloud cover, are different for the various forcing calculations, and as shown, for example, by Berntsen et al. (1997) these can have an impact on the forcing. In addition the ozone climatologies in the three models will differ. Hence, there is some additional model dependency apparent in the RF patterns beyond the differences caused by the basic ozone distributions from the CTMs, but the effect on the forcing pattern appears slight.

The range of global-mean forcings from each of the three codes is shown in Fig. 5 for each scenario and for each CTM. In general, for a particular CTM ozone change, the three 
Fig. 3. Annual mean net radiative forcing due to ozone for the NOx-Asia case as calculated with the two CTMs and the three GCMs.

Fig. 4. Annual mean net radiative forcing due to ozone for the NOx-Europe case as calculated with the two CTMs and the three GCMs.

forcing calculations agree reasonably well, to within about $10 \%$ of the average of the forcings. The individual model results are not shown, but in most cases the highest forcing comes from ECHAM4 and the lowest from LMD. As for the differences in the global-mean RF for the same scenario there are contributions from the differences in CTM ozone fields as well as from the forcing calculations. For an extreme case the total difference may range up to about $30 \%$, for example for the NOx-Asia
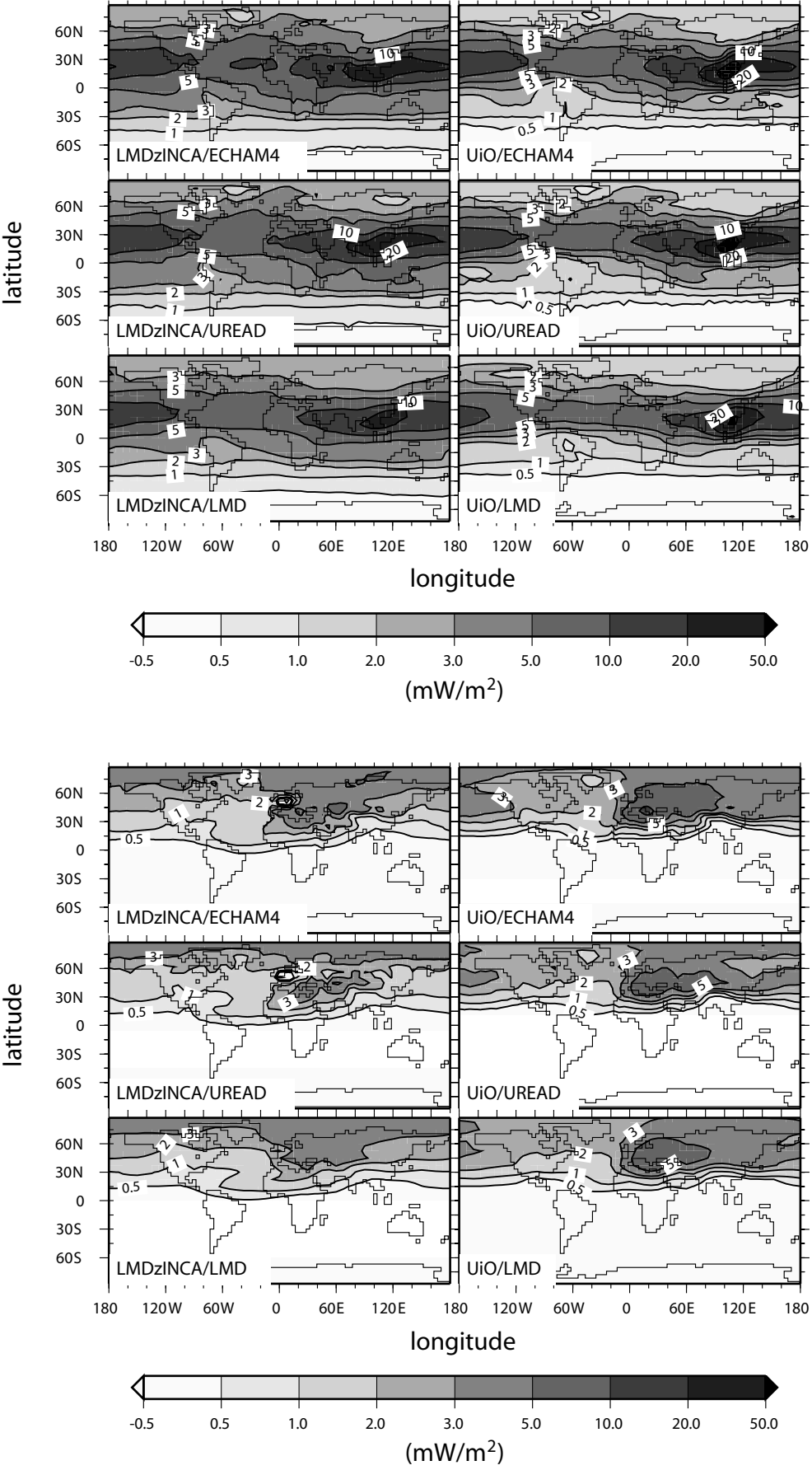

emission scenario the UiO/LMD pair yields a global-mean forcing of $4 \mathrm{~mW} \mathrm{~m}^{-2}$ while the LMDzINCA/ECHAM4 pair yields $6 \mathrm{~mW} \mathrm{~m}^{-2}$.

The radiative forcing of the steady-state methane perturbations (Table 3 ) is calculated by the simple formula given by IPCC (1990):

$\mathrm{RF}_{\mathrm{ss}}=\alpha\left[\left(C_{\mathrm{ss}}^{0.5}-\left(C_{0}\right)^{0.5}\right]-\left(f\left(C, N_{0}\right)-f\left(C_{0}, N_{0}\right)\right)\right.$. 


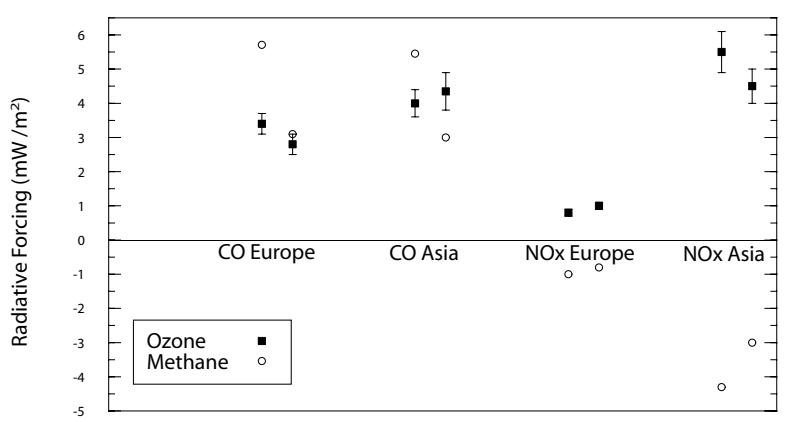

Fig. 5. Global-mean radiative forcing for the four emission cases. For each case, the left-hand set of symbols use the ozone changes from LMDzINCA and the right hand set use changes from UiO. For each scenario, the "error" bar shows the total range in the calculated ozone forcing using the three radiative transfer schemes.

The second term on the right hand side of the equation is a correction term for overlap with $\mathrm{N}_{2} \mathrm{O} . C_{\mathrm{ss}}$ is the perturbed mixing ratio of methane at steady state (ppbv) and $N$ is the mixing ratio of $\mathrm{N}_{2} \mathrm{O}$ (ppbv) and $C_{0}$ and $N_{0}$ are the concentrations for 1750. IPCC (1997) gives 0.036 for $\alpha$. Figure 5 shows the radiative forcings of methane for the eight experiments. Due to the very small changes in concentration, the effect of the non-linear relation between the concentrations and the forcing is very small and the differences between the forcings are proportional to the differences in the concentration perturbations.

For the CO cases, the forcing due to methane is almost independent of the location of the emission source, and the forcing is of the same sign and similar size to the ozone forcing. For $\mathrm{NO}_{\mathrm{x}}$ the methane-induced forcing is negative and, as with the ozone itself, is strongly dependent on the location of the emissions. The methane forcing opposes, at least on a global-mean basis, about $60-80 \%$ of the positive forcing due to ozone.

\section{Surface temperature response and climate sensitivity}

A selection of ozone perturbations produced by the CTMs has been imposed on two GCMs to simulate the equilibrium climate response. As mentioned previously, the work here builds on a previous study (Joshi et al., 2003) in which a wide range of idealized forcings were imposed on three GCMs to assess the degree to which the climate sensitivity parameter was dependent on the nature of the forcing mechanism. Of particular relevance is the finding of Joshi et al. (2003) that generally the sensitivity to high-latitude forcings is greater than to low-latitude forcings in both ECHAM4 and UREAD, supporting earlier conclusions by Hansen et al. (1997) and Forster et al. (2000). Joshi et al. (2003) also found that upper tropospheric ozone perturbations tend to yield a $20-40 \%$ lower climate sensitivity. More recently, Mickley et al. (2004) also found the climate sensitivity to both uniform and heterogeneous ozone changes to be $25 \%$ lower than that due to a change in carbon dioxide.
Table 4. Global-mean climate sensitivity parameter (in $\mathrm{K}\left(\mathrm{Wm}^{-2}\right)^{-1}$ ) for selected ozone change scenarios and for globally uniform change in either carbon dioxide or methane (see text for details). Values in parentheses are the ratio of the climate sensitivity for the particular case compared with the carbon dioxide value

\begin{tabular}{lcc}
\hline & ECHAM4 & UREAD \\
\hline Carbon dioxide & 0.81 & 0.38 \\
LMDzINCA NOx-Europe & $1.14(1.41)$ & $0.37(0.97)$ \\
UiO NOx-Europe & $1.20(1.48)$ & $0.39(1.03)$ \\
LMDzINCA NOx-Asia & $0.90(1.11)$ & $0.32(0.84)$ \\
LMDzINCA NOx-Asia/Europe & $1.01(1.25)$ & $0.32(0.84)$ \\
UiO CO-Europe & $1.00(1.23)$ & - \\
UiO CO-Asia & $0.90(1.12)$ & - \\
Methane & $0.87(1.08)$ & $0.36(0.95)$ \\
\hline
\end{tabular}

Because of limitations on computing time, it was only possible to use ozone changes from a subset of the CTM calculations. As summarized in Table 4, four NOx scenarios were chosen to be covered by both GCMs used for the climate simulations discussed in this paper (see Section 3); these were intended to illustrate the model dependency for a range of highly inhomogeneous forcing patterns and also to test the linearity of the response. The climate response of two $\mathrm{CO}$ scenarios was simulated in further experiments, but only with ECHAM4. As already mentioned, to ensure a statistically significant response of the change in global-mean surface temperature from the GCMs it was necessary to scale the ozone changes produced by the CTMs to give a global-mean $1 \mathrm{~W} \mathrm{~m}^{-2}$ forcing in each of the GCMs, which required different scaling factors due to the differences in the original RF values for the various cases (Fig. 5). The exception is the fourth idealized case in Table 4 in which the sum of two of the NOx scenarios is imposed but where the ozone change giving the $1 \mathrm{~W} \mathrm{~m}^{-2}$ change is retained. Here, the main intention is to test the additivity of the response of models when different forcing patterns are imposed simultaneously. It turns out that the forcing is not quite linear in ozone loading: The combined ozone change does not generate a $2 \mathrm{~W} \mathrm{~m}^{-2}$ forcing, but the two models give forcings of 1.84 and $1.90 \mathrm{~W} \mathrm{~m}^{-2}$, indicating a departure from non-linearity of no more than $8 \%$.

In most of the results presented in this section, the temperature responses have been rescaled by the inverse of the scaling factors that were applied to the actual forcing. This gives a more realistic indication of the response to the original emissions used in the CTMs (Table 1), and facilitates a direct comparison of the climate effect of equal emissions in the two regions. The fact that departure from non-linearity is less than $8 \%$ for the case forced with the sum of the two NOx scenarios also indicates that the rescaling of the GCM response to the original forcing is unlikely to be a major source of inconsistency when relating radiative forcing and temperature response for the various scenarios.

In addition to calculating the response of climate to ozone changes, the impact of a homogeneous change in methane is 
also computed because, as explained earlier, methane is affected by the changed emissions. We are not aware of other GCM calculations of the climate sensitivity to methane changes alone; Wang et al. (1991, 1992) and Govindasamy et al. (2001) have compared the climate sensitivity to increases in a range of wellmixed greenhouse gases, compared with equivalent $\mathrm{CO}_{2}$, with conflicting conclusions. Wang et al. (1991, 1992) showed that the global-mean sensitivity is similar in both cases, while Govindasamy et al. (2001) found that explicit consideration of the well-mixed gases led to a $20 \%$ increase in climate sensitivity. However, it is not possible to isolate the role of methane alone from these calculations. In the case of UREAD, a modified radiation code had to be used to include the impact of methane, which resulted in a different climate sensitivity. We calculated the $\mathrm{CO}_{2}$ and $\mathrm{CH}_{4}$ sensitivity using this modified code. So as to allow a comparison with the ozone experiments, we scaled the methane sensitivity by the ratio of the $\mathrm{CO}_{2}$ forcings in the original and modified radiation codes.

Table 4 shows the global-mean climate sensitivity for each of the selected cases, plus the value for a globally uniform change in carbon dioxide for reference. Comparing the two models, as we had found in our earlier work, there is a distinct difference in the climate sensitivities between the ECHAM4 and UREAD models. While the ECHAM4 model is significantly more sophisticated, it is not possible to claim that its climate sensitivity values are more reliable. Even for $\mathrm{CO}_{2}$ forcing alone, IPCC (2001) does not find convergence to a particular value of climate sensitivity as models become more complex, and the UREAD model remains in the range found in these more complex models.

Concerning the climate sensitivity of the ozone perturbations relative to carbon dioxide, Table 4 shows that the ratio departs from unity for both models, most markedly for ECHAM4. The climate sensitivity in response to a homogeneous $\mathrm{CH}_{4}$ increase is quite close to the $\mathrm{CO}_{2}$ value for two models. Within the sample of ozone experiments there is little agreement between the models as to how $\lambda$ differs from the $\mathrm{CO}_{2}$ value, but the general tendencies are consistent with the findings in Joshi et al. (2003).

Considering first the two European NOx scenarios, the models show almost identical sensitivity to both the LMDzINCA and $\mathrm{UiO}$ ozone changes; this is reassuring, as it indicates that the difference in patterns of ozone change from the two CTMs does not have much impact on climate sensitivity. For ECHAM4, the enhanced sensitivity is consistent with the finding of Joshi et al. (2003) that this model's northern extratropical forcings are $40 \%$ more effective than global forcings. In UREAD there appears to be more of a balance between the enhanced sensitivity for high-latitude forcings and the reduced sensitivity to tropospheric ozone forcings (see Joshi et al., 2003); these combine to yield a sensitivity similar to that for $\mathrm{CO}_{2}$.

For the NOx-Asia scenario, where the forcing peaks in the northern subtropics, the sensitivity relative to $\mathrm{CO}_{2}$ is reduced for UREAD but enhanced for ECHAM4. The ECHAM4 behaviour appears somewhat inconsistent with the performance of this model in Joshi et al. (2003), where it tended to show reduced sensitivity (compared with $\mathrm{CO}_{2}$ ) for a low-latitude tropospheric ozone perturbation. However, the perturbation used in Joshi et al. (2003) was essentially an upper tropospheric one, whereas the patterns used here span the lower to upper troposphere. The climate sensitivity to middle and lower troposphere ozone perturbations is about $10 \%$ higher than in the global $\mathrm{CO}_{2}$ case (Stuber et al., 2001); hence, these will oppose, to some extent, the decreased sensitivity to upper tropospheric ozone changes.

For the combined Asia and Europe NOx case, the climate sensitivity is between the two cases individually for both UREAD and ECHAM4, as could be expected. The significantly lower climate sensitivity in the UREAD simulation, in comparison with $\mathrm{CO}_{2}$, is consistent with the results of Mickley et al. (2004). However, it should be noted that their model as well as UREAD both have a significantly lower resolution than ECHAM4. The ECHAM4 model is generally more sensitive to the ozone perturbations, especially in the northern extratropics. The extra sensitivity to a radiative forcing that is so constrained to the Northern Hemisphere suggests that the response of sea ice to a geographically coincident radiative forcing in the ECHAM4 model is stronger than in UREAD. Finally, the two experiments run with ECHAM4 for the ozone changes arising from CO emission scenarios also confirm the behaviour typical for this GCM: a higher sensitivity to an extratropical (Europe) than to a tropical (Asia) perturbation. However, the differences are not as distinct as for the NOx scenarios, as is consistent with the smoother structure of the ozone change and radiative forcing patterns.

The annual-mean zonally averaged surface temperature response to ozone perturbations for the NOx-Europe cases (LMDzINCA and $\mathrm{UiO}$ results) and the NOx-Asia case (LMDzINCA only) is shown in Fig. 6. All the results show the same pattern of enhanced warming in the northern extratropics, consistent with our previous work, and show that the response is much larger in the hemisphere in which the radiative forcing occurs. The temperature response in the Southern Hemisphere is smaller, not only because the land-sea distribution generally favours a larger Northern Hemisphere response, but also because the forcing itself is largely constrained to the Northern Hemisphere. The ECHAM4 model has a response in the Southern Hemisphere of about 40 and $70 \%$ of the global mean in the NOx-Europe cases and NOx-Asia cases, respectively. The response of UREAD in the Southern Hemisphere is almost insignificant for the NOx-Europe cases, while for the NOx-Asia case the relative response is similar to the ECHAM4 model.

Figure 7 shows the geographical distribution in surface temperature response from the ECHAM4 model for the LMDzINCA $\mathrm{NO}_{\mathrm{x}}$-Europe and $\mathrm{NO}_{\mathrm{x}}$-Asia cases. Beyond the strong interhemispheric differences, there is little resemblance between the patterns of forcing (see Figs 3 and 4) and patterns of response; this is consistent with the view of Boer and Yu (2003) that the patterns of climate response are more driven by model feedbacks than by the forcing patterns. As in Fig. 6, the response for the NOx-Asia 


\section{LMDzINCA / NOx-Europe}

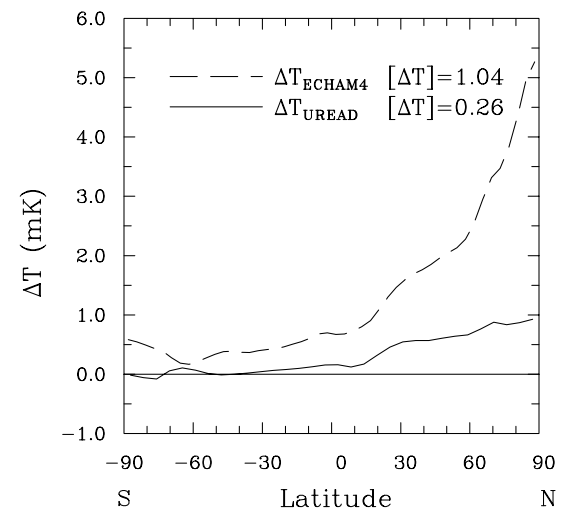

\section{$\mathrm{UiO} / \mathrm{NOx}$-Europe}

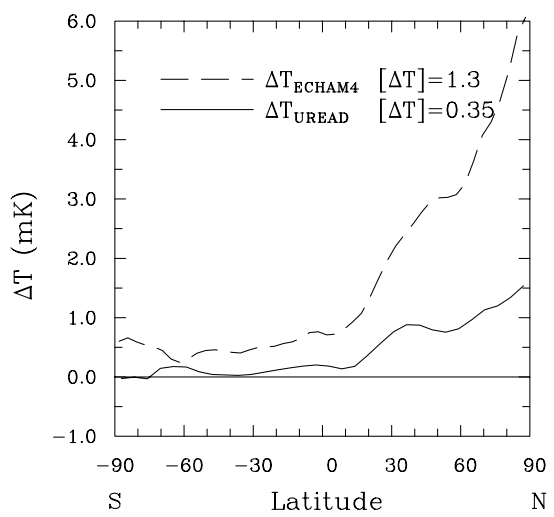

LMDzINCA / NOx-Asia

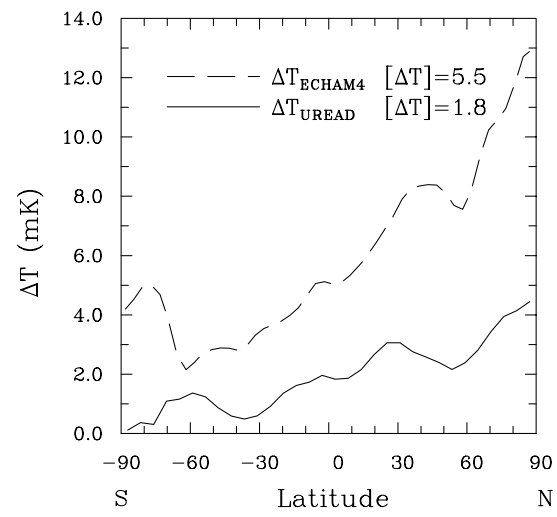

Fig. 6. Annually and zonally averaged surface temperature response (in $\mathrm{mK}$ ) for each of the driven ozone changes imposed on the two GCMs.

case generally exceeds that for the NOx-Europe case. The relative excess is strongest in low latitudes and weakest in northern polar latitudes due to the characteristic tendency of ECHAM4 to produce a large sea-ice response to a high-latitude forcing, which in this case compensates for part of the larger overall response in the NOx-Asia case.

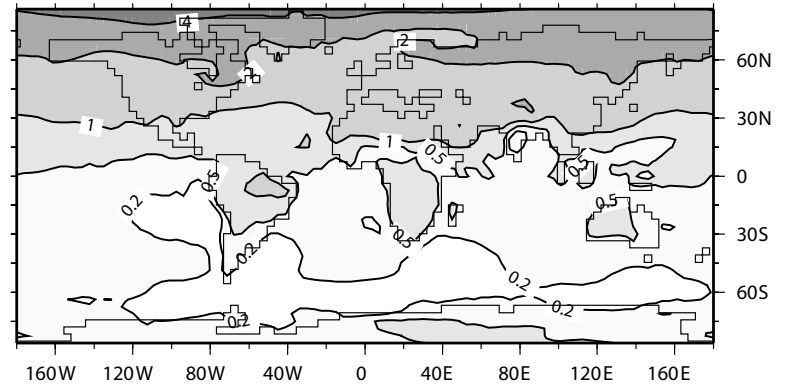

NOx-Asia (LMDzINCA/ECHAM4)
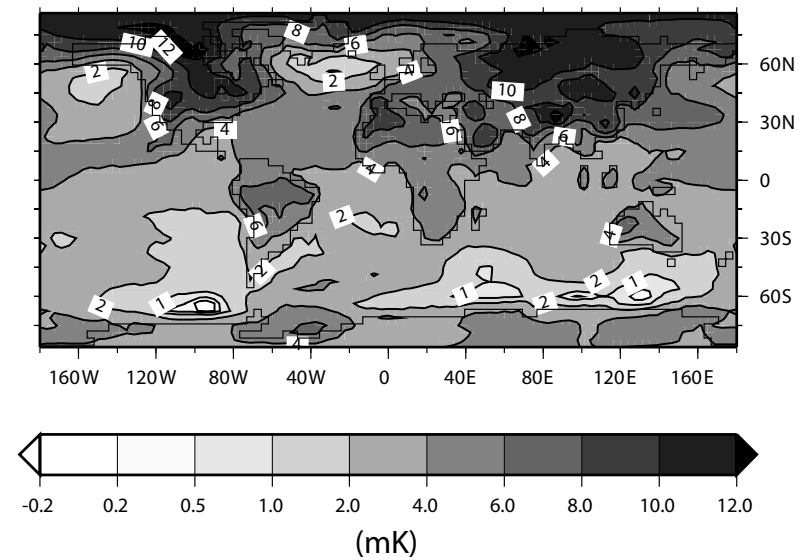

Fig. 7. Annually averaged surface temperature response for the ECHAM4 model for the LMDzINCA NOx-Europe and NOx-Asia cases.

The differences in zonal-mean surface temperature response between the UiO- and the LMDzINCA-based ozone changes for the European NOx emission scenarios are shown in Fig. 8. This gives an impression of how differences between CTMs that are forced with identical emission changes may affect the GCM results. Both GCMs agree in showing a larger temperature increase in the $\mathrm{UiO}$ case due to the larger radiative forcing (about 25\%) in this case ( $c f$. Fig. 5). The difference in the radiative forcing is then amplified in the temperature response due to the difference in the climate sensitivity between the two GCMs. The zonally averaged temperature differences are more or less proportional to the differences between the RF in the two cases; this indicates that when averaged over large areas, the GCMs are relatively insensitive to the details of the differences in the patterns generated by CTM when using the same emissions. The relatively small difference in the global climate sensitivity between these two cases ( 4 and $6 \%$ in the ECHAM4 and UREAD, respectively, cf. Table 4) supports this finding.

Non-linearities may occur in the response of the GCMs for the combined European and Asian cases. One of these has already 


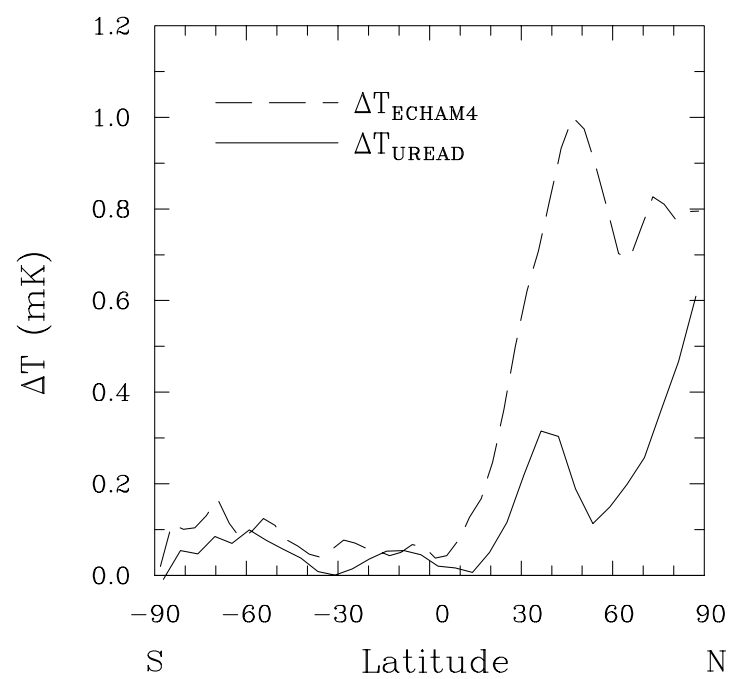

Fig. 8. Difference between the annually and zonally averaged surface temperature change (in $\mathrm{mK}$ ) for the UiO NOx-Europe and LMDzINCA NOx-Europe cases for the two GCMs.

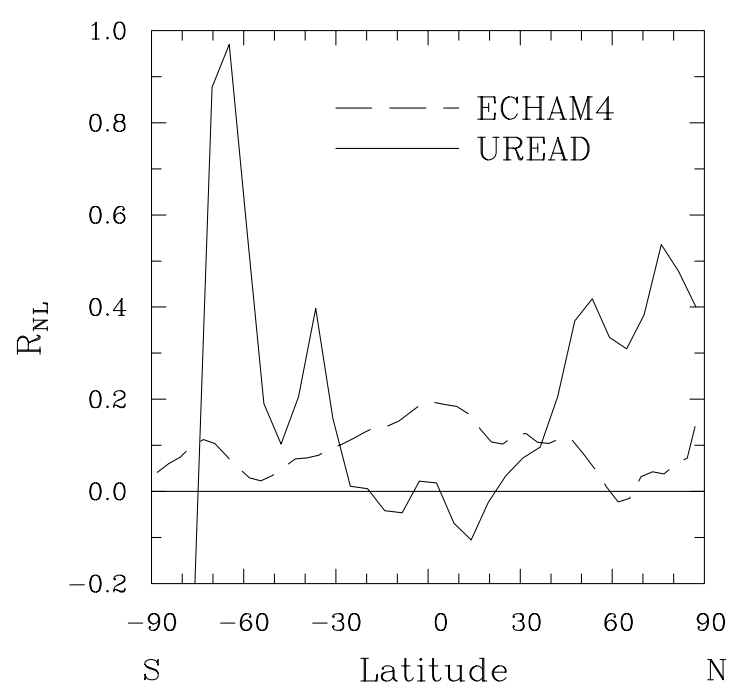

Fig. 9. Relative difference between the annually and zonally averaged surface temperature change between the sum of the responses to the LMDzINCA NOx Europe and Asia cases, and the response when two ozone perturbations are imposed together, for the two GCMs.

been mentioned above, which is reflected by the deviation of the radiative forcing of the sum of ozone perturbations from the sum of radiative forcings from each ozone perturbation. The second possible cause of non-linearity that deserves some attention in this context lies in the climate response of a GCM to a sum of different radiative forcing patterns. Figure 9 shows for both GCMs the difference between (1) the sum of the zonal-mean surface temperature changes yielded by each of the respective individual climate sensitivity simulations for either the NOxEurope or the NOx-Asia case and (2) the simulated zonal-mean surface temperature change in response to the sum of radiative forcings from the LMDzINCA bases European and Asian ozone scenarios. Recall that for this experiment the response shown is for the scaled ozone changes that yield a global-mean forcing of $1 \mathrm{~W} \mathrm{~m}^{-2}$. The indicator parameter, $R_{\mathrm{NL}}$, is calculated as

$R_{\mathrm{NL}}=[(\Delta T(\mathrm{EU})+\Delta T(\mathrm{As}))-\Delta T(\mathrm{EUAs})] / \Delta T(\mathrm{EUAs})$,

where $\Delta T(\mathrm{EU})$ and $\Delta T(\mathrm{As})$ denote the response in the NOxEurope and NOx Asia cases individually, and $\Delta T$ (EUAs) denotes the response when the two ozone fields are imposed on the GCMs together. In the global mean, the sum of the responses is slightly larger than the response to the sum of the forcings in the both models due to the lower total forcing in the combined case. ECHAM4 shows little latitudinal structure in $R_{\mathrm{NL}}$, whilst UREAD shows a distinct increase of $R_{\mathrm{NL}}$ at higher latitudes, indicating a higher non-linearity of feedbacks in the extratropics than in the tropics, where the response is almost perfectly linear. The overall conclusion is that the GCM responses are close to linear when two perturbations are imposed simultaneously.

An important conclusion from surveying the GCM results from the various climate sensitivity simulations is that the two GCMs do not yield a consistent picture as to whether the climate sensitivity to the ozone perturbation is higher or lower than that due to carbon dioxide-ECHAM4 always produces a higher sensitivity, whilst UREAD in most cases produces a lower sensitivity. This probably reflects the balance between differing strengths of feedbacks in the two models. For ECHAM4, the enhanced response to high-latitude forcings, and lower and middle tropospheric ozone forcings (Stuber et al., 2001, 2005), appears to dominate over the reduced response to upper tropospheric ozone forcings, whilst in the UREAD model the reduced response to upper tropospheric forcings seems to dominate. Hence we cannot, with any confidence, say if, or how, the climate sensitivity to an ozone perturbation differs from that due to carbon dioxide. Nevertheless, the models do display a significant consistency, in that the sensitivity to the Asian $\mathrm{NO}_{\mathrm{x}}$ emissions is about $80 \%$ of that for the Europe $\mathrm{NO}_{\mathrm{x}}$ emissions, a fact that we will use in the later analysis.

\section{A modified GWP for NOx and CO}

In the preceding sections we have demonstrated, in a quantitative sense, how differences in the geographical location of the emissions lead to differences in radiative forcing from ozone and methane. Due to the long lifetime compared with the timescale of the mixing of gases in the troposphere methane is well mixed, and perturbations in methane will be smoothed out. Ozone, on the other hand, has a response time of the order of weeks and shows a much more spatially heterogeneous response pattern with changes that are more confined to the regions of the emission perturbations. It was also demonstrated that the climate sensitivity to ozone and methane changes is probably different, and that it may depend on the location of the emissions for the case of ozone. In this section we discuss the consequences of these 
findings for evaluating the global effect of NOx and $\mathrm{CO}$ emissions in terms of a modified global warming potential (GWP).

\subsection{Limitations and possible enhancements of the GWP concept}

Based on the concept of radiative forcing, the Intergovernmental Panel on Climate Change (IPCC) has employed the metric GWP for quantitative comparison of the potential impact of different emissions (IPCC, 1990, 1992, 1995, 1996, 2001). The GWP is a relative measure and is defined as the time-integrated commitment to climate forcing from the instantaneous pulse release of $1 \mathrm{~kg}$ of a trace gas $i$ expressed relative to that of $1 \mathrm{~kg}$ of the reference gas $\mathrm{CO}_{2}$ :

$$
\begin{aligned}
\operatorname{GWP}(H)_{i} & =\frac{\int_{0}^{H} \mathrm{RF}_{i}(t) \mathrm{d} t}{\int_{0}^{H} \mathrm{RF}_{\mathrm{CO}_{2}}(t) \mathrm{d} t} \\
& =\frac{\int_{0}^{H} a_{i} c_{i}(t) \mathrm{d} t}{\int_{0}^{H} a_{\mathrm{CO}_{2}} c_{\mathrm{CO}_{2}}(t) \mathrm{d} t} \\
& =\frac{\mathrm{AGWP}_{i}}{\mathrm{AGWP}_{\mathrm{CO}_{2}}}
\end{aligned}
$$

where $H$ is the considered time horizon and $t$ is the time. The terms $a_{i}$ and $a_{\mathrm{CO}_{2}}$ are the radiative forcings due to an increase of one unit in atmospheric concentration of the gas $i$ and $\mathrm{CO}_{2}$, respectively; $c_{i}$ and $c_{\mathrm{CO}_{2}}$ are the respective time-decaying abundances of pulses of the injected gases. The terms $\mathrm{RF}_{i}$ and $\mathrm{RF}_{\mathrm{CO}_{2}}$ are the radiative forcings due to the agents $i$ and $\mathrm{CO}_{2}$. The absolute global warming potential (AGWP) for gas $i$ and the reference gas is given by the numerator and denominator, respectively. The climate sensitivity parameter $\lambda$ does not enter the definition of GWP. Thus, in the application of GWPs, $\lambda$ is implicitly assumed to be equal for all perturbations.

The GWP concept is well suited for gases with a sufficiently long lifetime to be well-mixed in the troposphere. The forcing from ozone changes is more heterogeneous than the forcing from the more long-lived gases like $\mathrm{CH}_{4}$ and $\mathrm{N}_{2} \mathrm{O}$. This fact, together with the complex links between ozone formation and the precursors, makes GWPs for NOx and CO uncertain and difficult to estimate. Furthermore, the effects on $\mathrm{O}_{3}$ and $\mathrm{CH}_{4}$ depend on the location and time of emissions. IPCC has not made firm recommendations for the GWPs for CO and NOx, but did review some recent attempts in the literature (Johnson and Derwent, 1996; Fuglestvedt et al., 1996; Daniel and Solomon, 1998; Derwent et al., 2001). Various approaches have been used (from simple to more complex models), and instead of using pulses of emissions (like in the definition of GWPs given by the IPCC) sustained (or step) emission changes have been considered in some cases. One additional complication related to the ozone precursors that has not been accounted for in the studies given above is the difference in the climate sensitivity parameter for ozone perturbations compared with $\mathrm{CO}_{2}$.
The IPCC GWPs are global with respect to the chosen key parameter (i.e. global-mean RF) and do not take into account the location of emissions. While this is not necessary for wellmixed greenhouse gases, calculation of GWPs for chemically active gases (e.g. ozone precursors) calls for a treatment of the significance of location; $c f$. Sections 4, 5 and 6. Several studies have shown how indirect RF from NOx emissions varies between different geographical regions (Johnson and Derwent, 1996; Fuglestvedt et al., 1999; Wild et al., 2001; Stevenson et al., 2004), and some studies have presented estimates of regional GWPs (Johnson and Derwent, 1996; Derwent et al., 2001).

A potential extension of the GWP concept is to account for the fact that the climate sensitivity parameter $\lambda$ may vary amongst different climate change mechanisms (Fuglestvedt et al., 2003). The definition of GWP could then be modified such that

$\operatorname{GWP}(H)^{*}=\frac{\int_{0}^{H} \lambda_{i} \mathrm{RF}_{i}(t) \mathrm{d} t}{\int_{0}^{H} \lambda_{\mathrm{CO}_{2}} \operatorname{RF}_{\mathrm{CO}_{2}}(t) \mathrm{d} t}=r \operatorname{GWP}(H)$

assuming that $\lambda_{i}$ and $\lambda_{\mathrm{CO} 2}$ do not change over time. In the case of source gases with indirect radiative forcing affecting both tropospheric $\mathrm{O}_{3}$ and $\mathrm{CH}_{4}$, the $\mathrm{RF}$ term can be split into two components and the GWP* can then be formulated as:

$$
\begin{aligned}
& \operatorname{GWP}(H)_{\text {net }}^{*} \\
& =\frac{\int_{0}^{H} \lambda_{O_{3}} \mathrm{RF}_{O_{3}}(t) \mathrm{d} t+\int_{0}^{H} \lambda_{C H_{4}} \mathrm{RF}_{C_{H_{4}}}(t) \mathrm{d} t}{\int_{0}^{H} \lambda_{\mathrm{CO}_{2}} \mathrm{RF}_{\mathrm{CO}_{2}}(t) \mathrm{d} t} \\
& =\operatorname{GWP}(H)_{\mathrm{O}_{3}}^{*}+\operatorname{GWP}(H)_{\mathrm{CH}_{4}}^{*} .
\end{aligned}
$$

In addition, the GWPs could also be modified to be based on sustained step increases in emissions and not pulses as in the definition given by IPCC. GWP values for sustained emissions (denoted as SGWP in the following) exist in the literature (Johnson and Derwent, 1996; Fuglestvedt et al., 1996). The various options for the calculation of GWPs discussed here are indicated in Table 5. Note that sustained emission changes can be regarded as a series of equal pulse emissions, so that the SGWP is equal to the integral of the GWP with decreasing time horizon:

$$
\begin{aligned}
\text { ASGWP } & =\int_{0}^{H} \int_{t}^{H} \operatorname{RF}\left(t^{\prime}, t\right) \mathrm{d} t^{\prime} \mathrm{d} t \\
& =\int_{0}^{H} \operatorname{AGWP}(H-t) \mathrm{d} t
\end{aligned}
$$

where $H$ is the time horizon and $R F\left(t^{\prime}, t\right)$ is the decaying radiative forcing of a pulse emitted at time $t$. The details are discussed in Appendix A. The effect of changing from pulse to sustained GWPs, which is a genuine policy question, can be regarded as committing future policy makers to use ever shorter time horizons in their metric as the time horizon is approached. This enhances the relative value of reducing short-lived species since there is a increasing contribution from high GWP values with short time horizons as $(H-t)$ approaches zero.

Since we are using results from steady-state simulations (in the CTMs and the GCMs) we will use the SGWPs in order to 
Table 5. Possibilities explored for the calculation of GWPs

\begin{tabular}{lcc}
\hline & \multicolumn{1}{c}{$r=1$} & $r \neq 1$ \\
\hline Pulse emission & Standard IPCC GWPs & \\
Sustained emissions & Johnson and Derwent (1996), & SGWP* for CO and NOx \\
& Fuglestvedt et al. (1996) & This work \\
\hline
\end{tabular}

account for differences in the climate sensitivity parameter $\lambda$ between the gases, i.e. the SGWP*. The relation between pulse and SGWPs are shown as the ratio between pulse GWPs and SGWPs as a function of $\mathrm{H}$ for idealized gases with selected lifetimes in Appendix A. (See also equations in Appendix B.)

For short lived gases the ratio is sensitive to the time horizon and after a century the pulse GWPs are significantly lower (by about $40 \%$ ) than the sustained ones. Thus for the gases studied here $\left(\mathrm{O}_{3}\right.$ and $\left.\mathrm{CH}_{4}\right)$ the ratio GWP/SGWP is sensitive to horizon, in particular for short time horizons. The SGWPs calculated below can be used to estimate pulse-based GWPs by multiplying the contribution from ozone (i.e. $\operatorname{SGWP}(100)_{\mathrm{O}_{3}}$ ) by 0.58 and the contribution from methane by 0.64 for a time horizon of $100 \mathrm{yr}$ (cf. Fig. 13).

Using the lifetimes and changes in lifetime for $\mathrm{CH}_{4}$ for the various cases and CTM runs given in Section 4, and a lifetime of 3.2 months for $\mathrm{O}_{3}$ (Berntsen et al., 1997), SGWP* accounting for radiative forcing from $\mathrm{O}_{3}$ and $\mathrm{CH}_{4}$ have been calculated (see Figs 10, 11 and 12). The excitation of the primary tropospheric chemical mode (Prather, 1996; Wild et al., 2001) has been accounted for. The details of the method for calculating the net SGWP are given in Appendix B. Radiative forcing from changes in stratospheric water vapour is not included in these calculations.

A general feature for the SGWP* for NOx emissions in $\mathrm{Eu}-$ rope and Asia is the opposing effects of $\mathrm{O}_{3}$ (warming) and $\mathrm{CH}_{4}$ (cooling) and the relatively sharp decline in the magnitude of the $\mathrm{O}_{3}$ effect as well as in the net effect as the time horizon exceeds

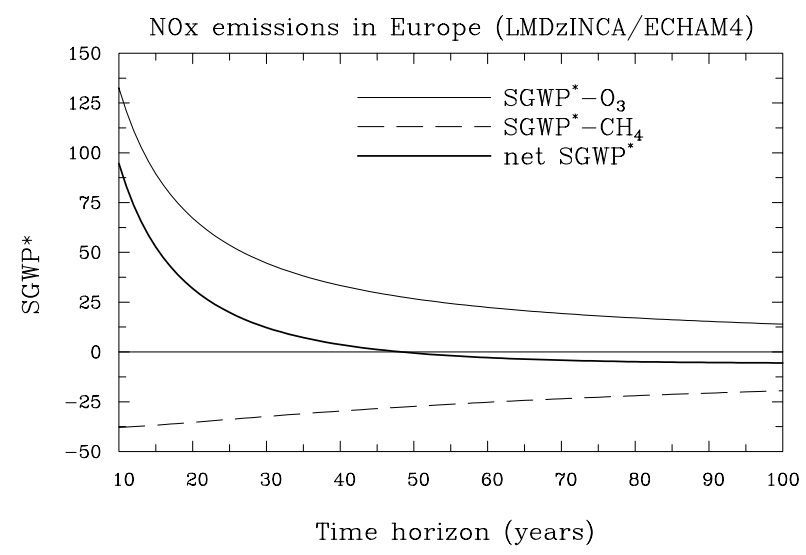

Fig. 10. Calculated SGWP* for NOx emissions in Europe as function of time horizon, based on results from LMDzINCA and ECHAM4.

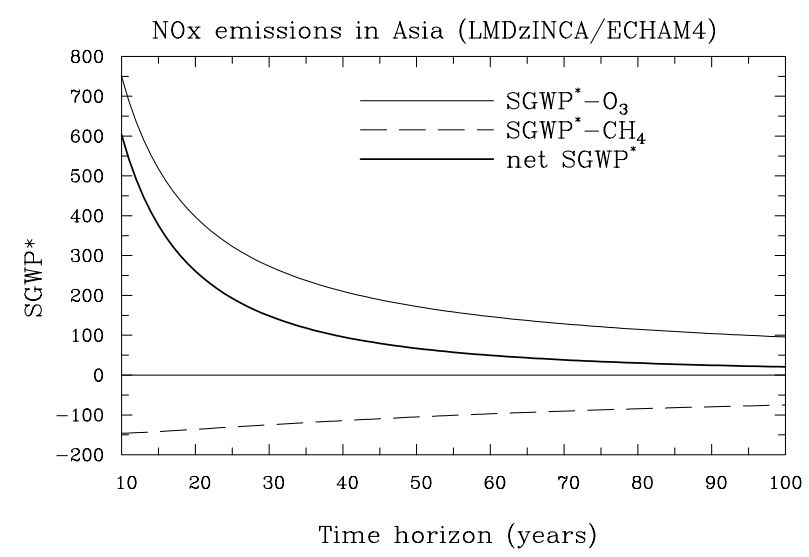

Fig. 11. Calculated SGWP* for NOx emissions in Asia as function of time horizon, based on results from LMDzINCA and ECHAM4. Note the difference in the scale of the $y$-axis in Fig. 10.

a few decades. The decline in SGWP* is caused by the accumulation of $\mathrm{CO}_{2}$ causing a steady increase of the denominator in eq. (2). In the case of European NOx emissions, the net effect approaches zero after a few decades and for the calculations with the LMDzINCA and UREAD the net effect is negative after about $50 \mathrm{yr}$.

Table 7 summarizes the calculated SGWP* values. For NOx emissions in Asia the effects via $\mathrm{O}_{3}$ and $\mathrm{CH}_{4}$ are larger than for Europe. For European NOx emissions the sign of the net effect is uncertain on a timescale of a century, while for Asian NOx emission the SGWP* are always positive. It should be noted that since the climate effect of $\mathrm{O}_{3}$ from NOx emissions in Asia as calculated by $\mathrm{UiO}$ was not determined with the GCMs, it is assumed that the climate sensitivity parameter derived for LMDzINCA also applies to the results from the UiO model.

The numbers in parentheses in Table 7 are obtained by setting $r=1$, i.e. not accounting for the differences in climate sensitivity parameters. For ECHAM4 these numbers are smaller, while for UREAD they are usually larger ( $c f$. Table 8$)$. In general, it can be concluded that introducing climate sensitivity parameters in metrics like GWP has relatively large effects on the calculated numbers. Thus, emissions of gases may be weighted quite differently if differences in the climate sensitivity are accounted for.

The net GWP or GWP* for NOx is sensitive to the balance between the radiative forcing of ozone and methane changes which, as shown in Fig. 5, largely oppose each other. An 

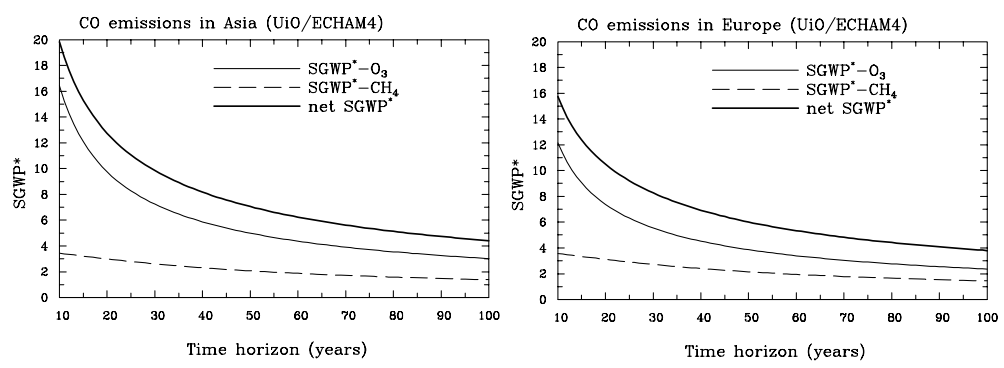

Fig. 12. SGWP* for $\mathrm{CO}$ emissions in Europe and Asia based on $\mathrm{UiO}$ and ECHAM4.

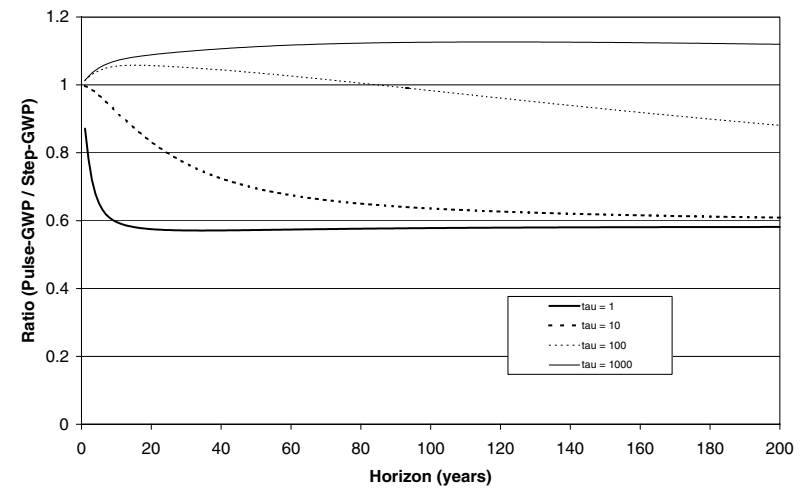

Fig. 13. Ratio between pulse-based and step-based GWPs as function of horizon for four selected lifetimes $(\tau)$.

Table 6. Absolute SGWP and SGWP* values for $\mathrm{CO}_{2}$

\begin{tabular}{|c|c|c|c|}
\hline \multirow[t]{2}{*}{$H(\mathrm{yr})$} & \multirow[t]{2}{*}{$\begin{array}{c}\text { SGWP } \\
\left(\mathrm{W} \mathrm{m}^{-2}\left(\mathrm{~kg} \mathrm{yr}^{-1}\right)^{-1} \mathrm{yr}\right)\end{array}$} & \multicolumn{2}{|c|}{$\begin{array}{c}\text { SGWP }^{*} \\
\left(\mathrm{~K}\left(\mathrm{~kg} \mathrm{yr}^{-1}\right)^{-1} \mathrm{yr}\right)\end{array}$} \\
\hline & & ECHAM4 & UREAD \\
\hline 20 & $2.912 \times 10^{-13}$ & $2.34 \times 10^{-13}$ & $1.11 \times 10^{-13}$ \\
\hline 100 & $5.185 \times 10^{-12}$ & $4.17 \times 10^{-12}$ & $1.97 \times 10^{-12}$ \\
\hline
\end{tabular}

Table 7. Calculated SGWP* values for $H=100 \mathrm{yr}$ for NOx emissions in Asia and Europe based on various combinations of models. The parentheses show the effect of setting $r=1$, i.e. not accounting for differences in climate sensitivities. The values are given on an N-basis. Divide by 3.28 to convert to an $\mathrm{NO}_{2}$ basis

\begin{tabular}{lccccc}
\hline & \multicolumn{2}{c}{ ECHAM4 } & & \multicolumn{2}{c}{ UREAD } \\
\cline { 2 - 3 } \cline { 5 - 6 } & UiO & LMDzINCA & & UiO & LMDzINCA \\
\hline$H=20$ yr & & & & \\
NOx-Europe & $56(32)$ & $32(15)$ & & $21(21)$ & $4.9(4.4)$ \\
NOx-Asia & $200(175)$ & $261(230)$ & $126(164)$ & $165(213)$ \\
$H=100$ yr & & & & \\
NOx-Europe & $6.9(1.6)$ & $-5.5(-8.1)$ & $-1.0(-1.3)$ & $-9.6(-10)$ \\
NOx-Asia & $25(21)$ & $21(17)$ & $9.7(18)$ & $2.9(12)$ \\
\hline
\end{tabular}

important question is to what extent differences in climate sensitivity can affect the degree of competition between the two forcings. Table 8 gives the ratios between the values of $\lambda$ for $\mathrm{O}_{3}$ and $\mathrm{CH}_{4}$ used in the calculations of SGWP*. Accounting for
Table 8. Ratio between climate sensitivity parameters used in the calculations of SGWP*

\begin{tabular}{lcc}
\hline & \multicolumn{2}{l}{ Ratio between sensitivity parameters } \\
\cline { 2 - 3 } & ECHAM4 & UREAD \\
\hline$\lambda_{\mathrm{O}_{3} / \lambda_{\mathrm{CH}_{4}} \text { NOx-Europe }}$ & 1.31 & 1.03 \\
$\lambda_{\mathrm{O}_{3}} / \lambda_{\mathrm{CH}_{4}}$ NOx-Asia & 1.03 & 0.89 \\
\hline
\end{tabular}

Table 9. SGWP* values for CO emissions in Europe and Asia based on $\mathrm{UiO}$ and ECHAM4. The parentheses show the effect of setting $r=1$, i.e. not accounting for differences in climate sensitivities

\begin{tabular}{lcc}
\hline & \multicolumn{2}{c}{ CO SGWP* } \\
\cline { 2 - 3 } & $20 \mathrm{yr}$ & $100 \mathrm{yr}$ \\
\hline CO-Europe & $10.5(8.8)$ & $3.8(3.2)$ \\
CO-Asia & $13(11)$ & $4.4(4.0)$ \\
\hline
\end{tabular}

climate sensitivity affects the weighting of the forcing by from a few per cent up to almost $50 \%$ for $\mathrm{O}_{3}$ relative to $\mathrm{CO}_{2}$, as in the case of European NOx emissions as modelled by $\mathrm{UiO}$ and ECHAM4 ( $c f$. Table 4). For $\mathrm{CH}_{4}$ the difference relative to $\mathrm{CO}_{2}$ is smaller ( $+9 \%$ for ECHAM4 and $-4 \%$ for UREAD; Table 4 ). The different sensitivities to $\mathrm{O}_{3}$ and $\mathrm{CH}_{4}$ are essential for the combined temperature effect and thus for the net SGWP* for NOx.

SGWP* values were also calculated for $\mathrm{CO}$ through responses in $\mathrm{O}_{3}$ and $\mathrm{CH}_{4}$, based on the results from $\mathrm{UiO}$ and ECHAM4. The net SGWP* for $\mathrm{CO}$ is always positive since the indirect effects through $\mathrm{O}_{3}$ and $\mathrm{CH}_{4}$ work in the same direction (see Fig. 12 and Table 9, as well as Fig. 5). Smaller differences in the chemical response between the regions ( $c f$. Section 4) also contribute to make the difference between the two regions (about 20\%) much less than for NOx. The SGWP*, including the climate sensitivity, are $10-15 \%$ higher than the corresponding SGWP values. Based on the differences in the climate sensitivity between the two GCMs for both methane- as well as NOx-driven ozone changes (Table 4), we expect that this enhancement is substantially model dependent. 


\subsection{Discussion}

Our estimates of SGWP* indicate that NOx emitted in Europe may have a significant climatic effect on a short timescale (years to a few decades) but that the effect becomes small and negative after about $50 \mathrm{yr}$. Given the large uncertainties, even the sign of the long-term net effect is also uncertain. For NOx emitted in Asia, however, the warming effect from ozone is more dominant and the net effect is larger. For this region, we can with a reasonable degree of confidence say that the net effect of NOx is warming, even on a century scale.

For comparison with previous estimates of GWPs for NOx we have done a simple conversion of our sustained SGWP* and SGWP as given in Table 7 to pulse-based GWP* and GWP by multiplying the contribution from ozone and methane ( $c f$. eq. 7.2) by a GWP/SGWP factor of 0.58 and 0.64 for ozone and methane respectively as derived from the results shown in Fig. 13 in Appendix A. Table 10 shows the net GWP* and GWPs for the NOx experiments for a time horizon of $100 \mathrm{yr}$. The estimated standard GWP values are either close to zero or negative for NOx emissions in Europe and consistently positive for NOx emissions in Asia across the models.

As GWPs for NOx are problematic to estimate and perhaps also controversial (e.g. Wuebbles, 1996; IPCC, 1999) few estimates are available in the literature. Johnson and Derwent (1996) used a 2-D model to calculate (sustained) GWPs for NOx. For the Northern Hemisphere and Southern Hemisphere, respectively, GWPs of 16 and -33 (on N-basis i.e. per kilogram of nitrogen in the $\mathrm{NO}_{\mathrm{X}}$ emissions) were calculated (for $100 \mathrm{yr}$ ). With a 3-D Lagrangian model Derwent et al. (2001) calculated pulse-based GWPs for the Northern Hemisphere and Southern Hemisphere, respectively. These were subject to a scaling error for ozone and have been reworked by Stevenson et al. (2004) to also include an updated concentration forcing relation for methane. The reworked GWP ${ }_{100}$ for NOx emitted in the Northern and Southern Hemispheres are then -1.2 and -2.9 (on N-basis). It should be noted that Derwent et al. (2001) have only calculated GWPs for January emission pulses, which might underestimate the positive (ozone) forcing. However, this is quite uncertain since the seasonal cycle of the net effect is determined by complicated interactions between chemistry, radiation and transport, as can be seen in the results for NOx from aircraft given by Stevenson

Table 10. GWP* and standard GWP values (in parentheses) for NOx and $\mathrm{CO}$ emissions in Europe and Asia with a $100 \mathrm{yr}$ time horizon

\begin{tabular}{lccccc}
\hline & \multicolumn{2}{c}{ ECHAM4 } & & \multicolumn{2}{c}{ UREAD } \\
\cline { 2 - 3 } \cline { 5 - 6 } \cline { 5 - 6 } & UiO & LMDzINCA & & UiO & LMDzINCA \\
\hline NOx-Europe & $3.1(0.1)$ & $-4.4(-5.8)$ & & $-1.4(-1.6)$ & $-6.6(-7.0)$ \\
NOx-Asia & $11.2(9.1)$ & $7.5(5.5)$ & & $2.7(7.4)$ & $-2.2(3.0)$ \\
CO-Europe & $2.3(1.9)$ & N.A. & & N.A & N.A \\
CO-Asia & $2.6(2.4)$ & N.A. & & N.A & N.A \\
\hline
\end{tabular}

et al. (2004) Here, the net RF for pulse emissions has been shown to be negative in January and July, while it is positive for April and October. Wild et al. (2001) have calculated pulse-based net integrated RF for NOx emissions in various regions, using annual pulse emission. Based on their numbers and an $\mathrm{AGWP}_{100}$ value for $\mathrm{CO}_{2}$ of $8.779 \times 10^{-14} \mathrm{~W} \mathrm{~m}^{-2} \mathrm{yr}\left(\mathrm{kg}\left(\mathrm{CO}_{2}\right) / \mathrm{yr}\right)^{-1}$ from IPCC (2001), GWP 100 values for NOx of -9.1 and -4.5 for European and East Asian emissions, respectively, can be derived. The magnitudes of our estimated GWPs are lower than the early 2-D-based estimates and in better agreement with more recent 3-D estimates. Compared with Wild et al. (2001) our results show the same tendency with respect to regional differences, although our results show net warming for the Asia case. The introduction of the SGWP* metric does not alter the picture dramatically, but introduces a dimension which increases the variation in the results. In spite of the differences between the various published estimates, progress has taken place with respect to clarification of the various dimensions and choices that are critical in the definition and construction of global climate metrics for NOx emission.

For CO we have only used one CTM and one GCM, which gives us a weaker basis for judging the robustness of these estimates. $\mathrm{CO}$ is, however, a simpler gas than NOx in the sense that the two indirect effects (via $\mathrm{CH}_{4}$ and $\mathrm{O}_{3}$ ) work in the same direction. We find smaller differences between the regions (of the order of 20-30\% difference between Europe and Asia) and the obtained values are in agreement with previous studies. Converting the SGWP* values to GWP* and standard GWPs as described for NOx above, we obtain pulse-based GWP*(100) values of 2.3 and 2.6 and standard GWP(100) values of 1.9 and 2.4 for $\mathrm{CO}$ emissions in Europe and Asia, respectively. Johnson and Derwent (1996) used a 2-D model and calculated a GWP of 2.1 for a time horizon of $100 \mathrm{yr}$ (for step changes in emissions), taking into account responses in tropospheric $\mathrm{O}_{3}$ and methane. Fuglestvedt et al. (1996) used a 2-D model and sustained step emission changes and calculated SGWP values of 10, 3 and 1 for the time horizons 20, 100 and $500 \mathrm{yr}$, respectively. Daniel and Solomon (1998) used a box model to calculate CO GWPs based on responses in $\mathrm{CH}_{4}$ and $\mathrm{O}_{3}$. For the time horizons 20, 50 and $100 \mathrm{yr}$ they calculated SGWPs in the ranges 2.8-14, 1.6-7.2 and 1-4.4, respectively, for pulse emissions of CO. With a 3-D Lagrangian model, Derwent et al. (2001) estimated 1.6 when responses in tropospheric ozone and methane were included for a time horizon of $100 \mathrm{yr}$ and pulse emissions. Thus, the results presented here for $\mathrm{CO}$ are in broad agreement with previously published numbers.

\section{Conclusions}

Two CTMs and three GCMs have been used to analyse the impact on climate of regional emission perturbations of the ozone precursors NOx and CO in Europe and southeast Asia. A sequence of model calculations has been performed to 
determine the impact of the various emission scenarios, starting with concentration changes for ozone and methane, followed by RF and, for some selected cases, full GCM simulations of equilibrium climate change. Finally, the results have been aggregated to a global climate change metric in three ways: First, through the application of a sustained step change in emissions (SGWP), second through a modified concept (SGWP*) which includes possible differences in the climate sensitivity of ozone, $\mathrm{CH}_{4}$, and $\mathrm{CO}_{2}$ changes and, finally, through estimated values for the standard GWP concept.

Comparison of the two CO cases and the two NOx cases simulated by the two CTMs (a total of eight simulations) shows that, in terms of total tropospheric ozone change, the models agree within $30 \%$. The agreement is better for the low-latitude (Asia) cases. The degree of model variation between the two CTMs is in agreement with results from Gauss et al. (2003) who compared results for 11 CTMs simulating the ozone change between 2000 and 2100 due to the SRES A2p emission scenario. Changes in concentrations of $\mathrm{OH}$ cause changes in the lifetime of methane and thus a radiative forcing. The agreement in terms of RF of methane between the CTMs was poorer (30-60\%) than for ozone (see Fig. 5). However, with a revised version of the LMDzINCA model, the agreement between the models was significantly improved to be at the same level as for ozone. Due to the high cost of the GCM simulations, the results from the revised version have not been propagated through to the GCMs. For the CO cases, and in particular the NOx cases, both CTMs are more sensitive to emission changes at low latitudes. In the $\mathrm{CO}$ cases the global and annual mean ozone burden enhancement increases by 8 and $40 \%$ (LMDzINCA and UiO, respectively), while for the NOx the ozone enhancement is a factor of 6.1 (LMDzINCA) and 3.6 (UiO) higher for the Asia cases.

To calculate the RF due to the ozone change, the 3-D ozone perturbations were used as input to the radiation transfer schemes of the GCMs. The details of the spatial structure of the resulting RF are mainly reflected in the respective patterns of ozone change. For a particular CTM ozone change, the global averages of the three forcing calculations agree reasonably well, to within about $10 \%$ of the average of the forcings. The sensitivities to emission perturbations at low versus high latitudes are further enhanced when we go from ozone burden to global-mean RF. For the CO cases the average RF (over three GCMs) is $17 \%$ (LMDzINCA) and 56\% (UiO) higher for the low-latitude perturbations, while for the NOx perturbations the enhancement in RF is a factor 7.0 and 4.8 for perturbations calculated by LMDzINCA and UiO respectively.

A selection of ozone perturbations produced by the CTMs has been scaled up to give a global-mean RF of $1 \mathrm{~W} \mathrm{~m}^{-2}$ and imposed on two of the GCMs to simulate the equilibrium climate response. One model (ECHAM4) gives consistently higher climate sensitivity to the ozone perturbations compared with $\mathrm{CO}_{2}$, while in the other one (UREAD) there is rather a tendency to give lower climate sensitivity for the ozone experiments compared with the $\mathrm{CO}_{2}$ experiment (except in the UiO-based NOx-Europe case). A range of different feedback processes contribute to the deviation of the climate sensitivity parameter from its value for carbon dioxide; this intermodel variability reflects the degree to which individual feedbacks are of different importance in the two GCMs. Based on these results we are not able to conclude whether real ozone perturbations in general have a different climate sensitivity compared with $\mathrm{CO}_{2}$ in the real world. Further model studies, and intercomparisons, will be needed with a wide range of GCMs. However, in both GCMs used here, high-latitude emission perturbations lead to climate perturbations with higher (10-30\%) climate sensitivities. This can be attributed to a stronger snow/ice response for perturbations with an RF pattern displaced towards higher latitudes. An interesting corollary of this finding is that the enhancement in sensitivity for low-latitude perturbations found through chemistry and forcing could be modestly ameliorated through higher climate sensitivity to higher-latitude emissions of short-lived species.

The results for the radiative forcing and climate sensitivities have been combined to study the possibilities of enhancing the concept of GWPs to better handle forcings caused by short-lived forcing agents (Section 7). A modified GWP for a sustainedstep emission change (SGWP*) which includes differences in the climate sensitivity is proposed to account for the fact that the climate sensitivity parameter $\lambda$ may vary amongst different climate change mechanisms.

For sustained emission changes we find that the SGWP* for NOx is significantly different from the SGWP value, while for CO the effect is much less. Since both the SGWP and SGWP* for NOx is a difference between a positive RF from ozone and a negative RF from methane of approximately equal magnitude, even relatively small differences in $\lambda$ can have large effects on the SGWP* values. With a time horizon of $20 \mathrm{yr}$ the SGWP* is positive for all our NOx emission cases. For the standard time horizon of $100 \mathrm{yr}$ all calculated SGWP* values for NOx emissions in Asia are positive, indicating a warming by enhanced NOx emissions, while for NOx emissions in Europe only the combination of the UiO CTM and the ECHAM GCM indicate a warming. However, even with the compensating effect of higher $\lambda$ for RF at higher latitudes, the SGWP* values are significantly higher for emissions of NOx in Asia compared with European emissions, mainly due to the higher chemical production efficiency. The calculated SGWP* values for the CO perturbations (only with the UiO/ECHAM model combination) seems to be much less regionally dependent (about 20\%). The difference between the ozone perturbations in the LMDzINCA model for the $\mathrm{CO}$-Europe and CO-Asia cases is smaller than in the $\mathrm{UiO}$ model, supporting this conclusion.

In terms of implications for possible inclusion of ozone precursors and short-lived species in future climate agreements, our results support the view that, for NOx, regionally different weighting factors for the emissions are necessary. For $\mathrm{CO}$ 
the results are more robust, and one global number may be acceptable. Calculating metrics for short-lived species inherently necessitates the use of CTMs or coupled-chemistry GCMs, and thus the derived numbers will be more model dependent than metrics for longer-lived species. We find that for the ozone impact from NOx emissions, the CTMs (through chemical sensitivity) and GCMs (through climate sensitivity) are about equal as sources of uncertainty (or model dependency, 30-50\% each), while the calculation of RF given an ozone perturbation field adds another $10 \%$. For the methane effect of NOx, the difference between the GCMs is smaller (15\%). Due to the fact that the net effect is a difference between two numbers of almost equal magnitude (at least for $H=100 \mathrm{yr}$ ), the uncertainty can become substantial and become a major obstacle in a negotiation process even if the uncertainties in the ozone and methane effects separately appear to be acceptable. Noting that the SGWP* of NOx for $H=20 \mathrm{yr}$ is much less model dependent (due to the dominating role of ozone on this timescale), a climate agreement with dual foci on both short-term decrease in the rate of climate change and a long-term goal on maximum level of temperature increase could include NOx in the short-term perspective using the $H=20 \mathrm{yr}$ time horizon as suggested by Fuglestvedt et al. (2000). Thus the answer to whether NOx emissions can be included in a comprehensive approach in a climate agreement depends on the characteristics and overall purpose of the treaty.

\section{Acknowledgments}

This work has received funding from the European Union (me $\tau$ ri ${ }^{\circ}$ C project, EVK2-CT-1999-00021), the Research Council of Norway and Deutscher Akademischer Austauschdienst.

\section{Appendix A: Relationship between pulse and sustained GWP}

We have noted (Section 7.2) that sustained emission changes can be regarded as a series of equal pulse emissions (sp), so that

$$
\begin{aligned}
\operatorname{AGWP}_{\mathrm{sp}} & =\int_{0}^{H} \int_{t}^{H} \operatorname{RF}\left(t^{\prime}, t\right) \mathrm{d} t^{\prime} \mathrm{d} t \\
& =\int_{0}^{H} \operatorname{AGWP}(H-t) \mathrm{d} t
\end{aligned}
$$

where $H$ is the time horizon and $\mathrm{RF}\left(t^{\prime}, t\right)$ is the decaying radiative forcing of a pulse emitted at time $t$. AGWP denotes standard pulse-based absolute GWPs.

A formulation for a sustained GWP can also be derived based on continuous emissions (ASGWP), in contrast to a series of pulse emissions. Below we show that for a gas with a single lifetime $\tau$ the expressions for ASGWP and $\mathrm{AGWP}_{\mathrm{sp}}$ are equal. The concentration as a function of time for a sustained emission change (one unit per year) is given by

$\Delta C(t)=\tau\left(1-\mathrm{e}^{-t / \tau}\right)$ and the ASGWP for a sustained emission change is then given by

$$
\begin{aligned}
\operatorname{ASGWP} & =\int_{0}^{H} A \tau\left(1-\mathrm{e}^{-t / \tau}\right) \mathrm{d} t \\
& =A \tau\left[H-\tau\left(1-\mathrm{e}^{-H / \tau}\right)\right]
\end{aligned}
$$

where $A$ is the radiative forcing per concentration unit.

For a series of pulse emissions (one unit emission per year), the concentration change for each pulse (emitted at time $t$ ) is given by

$$
\Delta C\left(t^{\prime}, t\right)=\mathrm{e}^{-\left(t^{\prime}-t\right) / \tau} \quad \text { for } t<t^{\prime} .
$$

The $\mathrm{AGWP}_{\mathrm{sp}}$ for this series of pulses is then given by

$$
\begin{aligned}
\operatorname{AGWP}_{\mathrm{SP}} & =\int_{0}^{H} \int_{t}^{H} A \mathrm{e}^{-\left(t^{\prime}-t\right) / \tau} \mathrm{d} t^{\prime} \mathrm{d} t \\
& =\int_{0}^{H} A t\left(1-\mathrm{e}^{-(H-t) / \tau}\right) \mathrm{d} t \\
& =A \tau\left[H-\tau\left(1-\mathrm{e}^{-H / \tau}\right)\right]
\end{aligned}
$$

which is exactly equal to the ASGWP as given by eq. (A.3).

To illustrate the difference between pulse and sustained GWPs we have performed a calculation of GWP and SGWP for a gas with a standard exponential decay according to $\mathrm{e}_{i}^{-t / \tau}$. For the reference gas $\mathrm{CO}_{2}$, the concentration response to a pulse or step emission is more complex. In many applications in the literature this response, $R(t)$, derived from more complete carbon cycle models, has been approximated by

$$
R(t)=a_{0}+\sum_{i} a_{i} \exp \left(-\frac{t}{\tau_{i}}\right) .
$$

In this work, we use the four-term representation derived from the Bern carbon cycle model (Joos et al., 1996) for the case of a constant future mixing ratio. For (A.6) the coefficients are $a_{0}=0.1756, a_{1}=0.1375, a_{2}=0.1858, a_{3}=0.2423$ and $a_{4}=$ 0.2589. $\tau_{1}=421.093, \tau_{2}=70.5965, \tau_{3}=21.4216, \tau_{4}=3.4154$ (all $\tau$ values are in years). (These coefficients were provided by F. Joos (personal communication) using the model of Joos et al. (1996) and are a fit to the same response function as used by IPCC (2001). See also Shine et al. (2005).) The same response function, in a different mathematical form, was used in IPCC (1996, 2001). Figure 13 shows the ratio between pulse GWP and sustained GWP for idealized gases with selected lifetimes.

\section{Appendix B: SGWP* for NOx and CO emissions}

This appendix shows how the results on chemical responses (Section 4), radiative forcing (Section 5) and climate sensitivities (Section 6) have been used for calculations of SGWP* for NOx and $\mathrm{CO}$ emissions in Asia and Europe. 
The equation for the change in concentration $(C)$ of a gas with time, where $P$ is emission and $L$ is the loss rate $(L=1 / \tau)$

$\frac{\mathrm{d} C}{\mathrm{~d} t}=P-L C$

can be integrated to give

$C(t)=\frac{P+\Delta P}{L}+\left(C_{0}-\frac{P+\Delta P}{L}\right) \mathrm{e}^{-t / \tau}$

Since $P / L=C_{0}$ and $C_{\mathrm{ss}}=(P+\Delta P) / L$, the change in concentration $\Delta C(t)$ is then given by:

$\Delta C(t)=C(t)-C_{0}=\left(C_{\mathrm{ss}}-C_{0}\right)\left(1-\mathrm{e}^{-t / \tau}\right)$

The term in the final parenthesis will describe the time evolution of the concentration towards steady state. We have already calculated $\Delta \mathrm{C}$ at steady state $\left(\Delta C_{\mathrm{ss}}\right)$ and the RF it has caused, and thus we need only the time development factor to describe the development of the radiative forcing with time. By integrating the latter expression for $\Delta C(t)$ we obtain:

$\int_{0}^{H} \Delta C(t) \mathrm{d} t=\left(C_{\mathrm{ss}}-C_{0}\right)\left[H-\tau\left(1-\mathrm{e}^{-H / \tau}\right)\right]$

and we find that the time development of the integrated RF can be described by the term in the last parentheses in eq. (B.4). The absolute SGWP* for gas $\mathrm{CH}_{4}$ can then be calculated by

$\operatorname{ASGWP}_{i}^{*}(H)=\lambda_{i} \operatorname{RF}_{i}\left[H-\tau_{i}\left(1-\mathrm{e}^{-H / \tau_{i}}\right)\right]$

for the various horizons.

For ozone we must modify eq. (B.3) to take into account that in our CTM experiments we keep methane concentrations fixed at observed current levels. This causes an artificial increase/decrease in production of peroxy radicals and thus ozone production, caused by the increase/decrease of $\mathrm{OH}$ through the $\mathrm{NOx} / \mathrm{CO}$ emissions. In the real situation where methane is not fixed, the change in the production of peroxy radicals would come back to its unperturbed values as the methane concentration approached its new steady-state level ( $c f$. Wild et al., 2001). Figure 14 shows a schematic illustration of the time development of ozone in a simulation of sustained emission change of NOx. For CO the $\Delta \mathrm{O}_{3}$ (net; ozone and methane) is above the $\Delta \mathrm{O}_{3}(\mathrm{sl}$; short lived mode for ozone) The difference between $\Delta \mathrm{O}_{3}(\mathrm{sl})$ and $\Delta \mathrm{O}_{3}$ (net) approaches a steady-state value with the same time constant as the methane response (i.e. the primary mode time constant of the system (Prather, 1996; Wild and Prather, 2000)).

Our simulations with fixed methane levels give us $\Delta \mathrm{O}_{3}(\mathrm{sl})$ (Table 2), and $\Delta \mathrm{CH}_{4}$ at steady state (Section 4.1 and Table 3). To estimate the difference between $\Delta \mathrm{O}_{3}($ net $)$ and $\Delta \mathrm{O}_{3}(\mathrm{sl})$ (i.e. $\delta \Delta \mathrm{O}_{3}$, the ozone perturbation caused by the reduction in methane) when the system has reached a new steady state, we have used results from the OXCOMP experiment (IPCC, 2001; Gauss et al., 2003). In OXCOMP the ozone response to a $10 \%$ enhancement in methane was calculated using six global 3-D CTMs. We have used the average response of 0.64 DU addi-

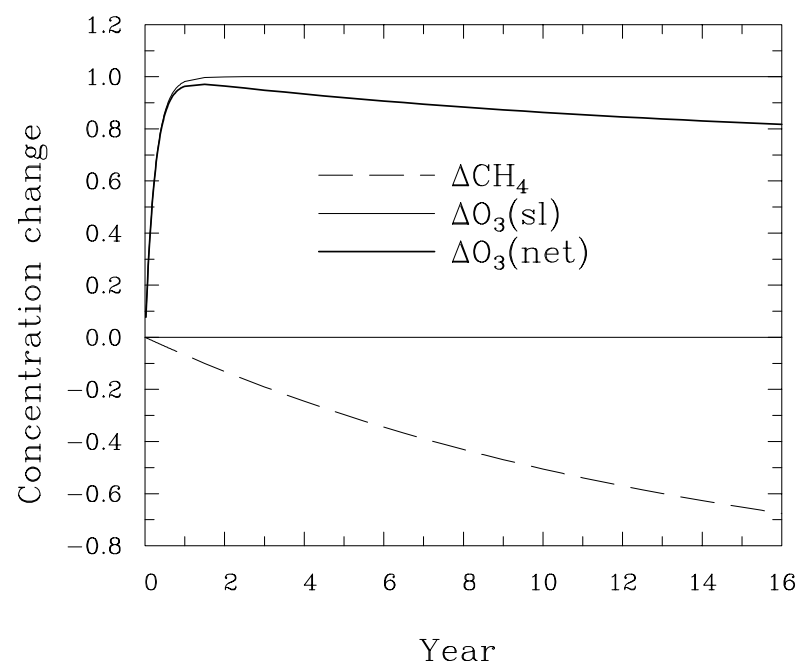

Fig. 14. Schematic illustration of the time development of ozone and methane in sustained emission change simulation.

tional ozone and our calculated methane response (Table 3) to estimate $\delta \Delta \mathrm{O}_{3}$.

$$
\begin{aligned}
\delta \Delta \mathrm{O}_{3} & =\left(\frac{\mathrm{dCH}_{4}}{\mathrm{CH}_{4}}\right)_{\text {thiswork }}\left(\frac{\mathrm{dO}_{3}}{\mathrm{dCH}_{4} / \mathrm{CH}_{4}}\right)_{\text {OXCOMP }} \\
& =\left(\frac{\mathrm{dCH}_{4}}{\mathrm{CH}_{4}}\right)_{\text {thiswork }} \frac{0.64 \mathrm{DU}}{0.1}
\end{aligned}
$$

Values of $\delta \Delta \mathrm{O}_{3}$ for the two CTMs and the four emission perturbation experiments are given in Table 11.

Time development of the net ozone perturbation is then given by

$$
\begin{aligned}
\Delta \mathrm{O}_{3}(t)= & \Delta \mathrm{O}_{3}(\mathrm{sl})\left(1-\mathrm{e}^{\left(-t / \tau_{1}\right)}\right) \\
& +\delta \Delta \mathrm{O}_{3}\left(1-\mathrm{e}^{-t / \tau_{1}}\right)\left(1-\mathrm{e}^{-t / \tau_{\mathrm{pm}}}\right)
\end{aligned}
$$

where $\tau_{1}$ is the assumed lifetime of ozone $(0.267 \mathrm{yr})$ and $\tau_{\mathrm{pm}}$ is the primary mode time constant of our system defined as $\tau_{\mathrm{pm}}=$ $1.4\left(\tau+\Delta \tau_{0}\right)(c f$. Section 4.1).

Based on eq. (A.6) for $\mathrm{CO}_{2}$, the change in $\mathrm{CO}_{2}$ concentration due to a sustained step emission change can be calculated by the convolution integral:

$\Delta C(t)=\int_{0}^{t} \Delta P^{\mathrm{CO} 2}\left[a_{0}+\sum_{i} a_{i} \exp \left(\frac{t^{\prime}-t}{\alpha_{i}}\right)\right] \mathrm{d} t^{\prime}$

Table 11. Calculated difference $\left(\delta \Delta \mathrm{O}_{3}\right)$ in tropospheric ozone mass (units of $\mathrm{Tg}$, in \% in parentheses) for the two CTMs due to the experimental set-up keeping methane fixed

\begin{tabular}{lcc}
\hline & $\begin{array}{c}\mathrm{UiO}, \delta \Delta \mathrm{O}_{3} \\
{\left[\mathrm{Tg}\left(\% \text { of } \Delta \mathrm{O}_{3}(\mathrm{sl})\right)\right]}\end{array}$ & $\begin{array}{c}\text { LMDzINCA, } \delta \Delta \mathrm{O}_{3} \\
{\left[\mathrm{Tg}\left(\% \text { of } \Delta \mathrm{O}_{3}(\mathrm{sl})\right)\right]}\end{array}$ \\
\hline CO-Europe & $0.27(46)$ & $0.49(63)$ \\
CO-Asia & $0.26(31)$ & $0.47(56)$ \\
NOx-Europe & $-0.072(-28)$ & $-0.096(-51)$ \\
NOx-Asia & $-0.26(-28)$ & $-0.37(-32)$ \\
\hline
\end{tabular}


which can be further integrated and multiplied with $\lambda_{\mathrm{CO} 2}$ and forcing strength $A$ to give (assuming $\Delta P$ equal to unity):

$$
\begin{aligned}
& \mathrm{ASGWP}_{\mathrm{CO} 2}^{*} \\
& \quad=\lambda_{\mathrm{CO} 2} A \int_{0}^{H} \Delta C(t) \mathrm{d} t \\
& =\lambda_{\mathrm{CO} 2} A\left(a_{0} \frac{1}{2} H^{2}+\sum_{i=1}^{n} \tau_{i} a_{i}\left(H+\tau_{i} \mathrm{e}^{-H / \tau_{i}}\right)-\tau_{i}\right)
\end{aligned}
$$

where $A$ is the forcing per change in mass units of $\mathrm{CO}_{2}$ in the atmosphere $\left(1.98 \times 10^{-15} \mathrm{~W} \mathrm{~m}^{-2} \mathrm{~kg}^{-1}\right)$. Table 6 gives the obtained absolute SGWP and SGWP* values for $\mathrm{CO}_{2}$.

\section{References}

Berntsen, T., Fuglestvedt, J. S., Myhre, G., Stordal, F. and Berglen, T. F. 2005. Abatement of greenhouse gases: does location matter? Climatic Change (in press).

Berntsen, T., Gauss, M., Isaksen, I. S. A., Grewe, V., Sausen, R. and co-authors 2003. Sources of NOx at cruise altitudes: implications for predictions of ozone and methane perturbations due to NOx from aircraft. In: Proceedings of the 'Aviation, Atmosphere and Climate (AAC) Conference, Friedrichshafen, Germany (http://www. pa.op.dlr.de/aac/proceedings/AAC-proceedings-chemistry.pdf).

Berntsen, T. and Isaksen, I. S. A. 1997. A global 3-D chemical transport model for the troposphere: 1 . Model description and $\mathrm{CO}$ and ozone results. J. Geophys. Res. 102, 21 239-21 280.

Berntsen, T. and Isaksen, I. S. A. 1999. Effects of lightning and convection on changes in tropospheric ozone due to NOx emissions from aircraft. Tellus 51B, 766-788.

Berntsen, T., Isaksen, I. S. A., Fuglestvedt, J. S., Alsvik Larsen, T., Stordal, F. and co-authors 1997. Effects of anthropogenic emissions on tropospheric ozone and its radiative forcing. J. Geophys. Res. 102, 28 101-28 126.

Boer, G. J. and Yu, B. 2003. Climate sensitivity and response. Clim. Dynam. 20, 415-429.

Christiansen, B. 1999. Radiative forcing and climate sensitivity: the ozone experience. Q. J. R. Meteorol. Soc. 125, 3011-3035.

Collins, W. J., Derwent, R. G., Johnson, C. E. and Stevenson, D. S. 2001. The oxidation of organic compounds in the troposphere and their global warming potentials. Climatic Change 52, 453-479.

Crutzen, P. J. 1987. Role of the tropics in atmospheric chemistry. In: The Geophysiology of Amazonia (ed. R. E. Dickinson). John Wiley, New York, 107-130.

Daniel, J. and Solomon, S. 1998. On the climate forcing by carbon monoxide. J. Geophys. Res. 103, 13 249-13260.

Derwent, R. G., Collins, W. J., Johnson, C. E. and Stevenson, D. S. 2001. Transient behaviour of tropospheric ozone precursors in a global 3-D CTM and their indirect greenhouse effects. Climatic Change 25, 1-25.

Forster, P. M., Blackburn, M., Glover, R. and Shine, K. P. 2000. An examination of climate sensitivity for idealised climate change experiments in an intermediate general circulation model. Clim. Dynam. 16, 833-849.

Fuglestvedt, J. S., Berntsen, T., Godal, O., Sausen, R., Shine, K. P. and co-author 2003. Metrics of climate change: assessing radiative forcing and emission indices. Climatic Change 58, 267-331.
Fuglestvedt, J. S., Berntsen, T. K., Isaksen, I. S. A., Mao, H., Liang, X.-Z. and co-author 1999. Climatic effects of NOx emissions through changes in tropospheric $\mathrm{O}_{3}$ and $\mathrm{CH}_{4}$-a global 3-D model study. Atmos. Environ. 33, 961-977.

Fuglestvedt, J. S., Isaksen, I. S. A. and Wang, W.-C. 1996. Estimates of indirect global warming potential for $\mathrm{CH}_{4}, \mathrm{CO}$ and NOx. Climatic Change 34, 404-437.

Fuglestvedt, J. S., Skodvin, T., Godal, O. and Berntsen T. 2000. Climate implications of GWP-based reductions in greenhouse gas emissions. Geophys. Res. Lett. 27, 409-412.

Gauss, M., Myhre, G., Pitari, G., Prather, M. J., Isaksen, I. S. A. and co-authors. 2003. Radiative forcing in the 21 st century due to ozone changes in the troposphere and the lower stratosphere. J. Geophys. Res. 108, 4292, doi:10.1029/2002JD002624.

Govindasamy, B., Taylor, K. E., Duffy, P. B., Santer, B. D., Grossman, A. S. and co-author 2001. Limitations of the equivalent $\mathrm{CO}_{2}$ approximation in climate change simulations. J. Geophys. Res. 106(D19), 22 593-22 604, doi:10.1029/2000JD000054.

Hansen, J., Sato, M. and Ruedy R. 1997. Radiative forcing and climate response. J. Geophys. Res. 102, 6831-6864.

Hauglustaine, D. A., Hourdin, F., Jourdain, L., Filiberti, M.-A., Walters, S. and co-authors 2004. Interactive chemistry in the Laboratoire de Météorologie Dynamique general circulation model: description and background tropospheric chemistry evaluation. J. Geophys. Res. 109, D04314, doi:10.1029/2003JD003957.

Hesstvedt, E., Hov, Ø. and Isaksen, I. S. A. 1978. Quasi steady-state approximation in air pollution modelling: comparison of two numerical schemes for oxidant prediction. Int. J. Chem. Kinet. X, 971-994.

Holtslag, A. A. M., DrBruijn, E. I. F and Pan, H.-L. 1990. A high resolution air mass transformation model for short-range weather forecasting. Mon. Weather Rev. 118, 1561-1575.

Hourdin, F. and Armengaud, A. 1999. The use of finite-volume methods for atmospheric advection of trace species. Part I: Test of various formulations in a general circulation model. Mon. Weather Rev. 127, $822-837$.

Intergovernmental Panel on Climate Change (IPCC): 1990. Climate Change. The Scientific Assessment. Cambridge University Press, Cambridge.

Intergovernmental Panel on Climate Change (IPCC): 1992. Climate Change. The Supplementary Report to the IPCC Scientific Assessment. Cambridge University Press, Cambridge.

Intergovernmental Panel on Climate Change (IPCC): 1995. Climate Change 1994. Radiative Forcing of Climate Change and an Evaluation of the IPCC IS92 Emission Scenarios. Cambridge University Press, Cambridge.

Intergovernmental Panel on Climate Change (IPCC): 1996. Climate Change 1995. The Science of Climate Change. Cambridge University Press, Cambridge.

Intergovernmental Panel on Climate Change (IPCC). 1997. An Introduction to Simple Climate Models Used in the IPCC Second Assessment Report. IPCC Technical Paper II. Cambridge University Press, Cambridge.

Intergovernmental Panel on Climate Change (IPCC). 1999. Aviation and the Global Atmosphere-A Special Report of IPCC Working Groups $I$ and III (eds. J. E. Penner et al.). Cambridge University Press, Cambridge. 
Intergovernmental Panel on Climate Change (IPCC): 2001, Climate Change 2001-The Scientific Basis (eds. J. T. Houghton, Y. Ding, D. J.Griggs, M. Noguer, P. J. van der Linden and D. Xiaoxu). Cambridge University Press, Cambridge.

Isaksen, I. S. A., Hov, Ø. and Hesstvedt, E. 1978. Ozone generation over rural areas. Environ. Sci. Technol. 12, 1279-1284.

Jacob, D. J., Prather, M. J., Rasch, P. J., Shia, R. -L., Balkanski, Y. and coauthors. 1997. Evaluation and intercomparison of global atmospheric transport models using ${ }^{222} \mathrm{Rn}$ and other short-lived tracers. J. Geophys. Res. 102, 5953-5970.

Johnson, C. E. and Derwent, R. G. 1996. Relative radiative forcing consequences of global emissions of hydrocarbons, carbon monoxide and NOx from human activities estimated with zonally-averaged two-dimensional model. Climatic Change 34, 439-462.

Joos, F., Bruno, M., Fink, R., Stocker, T. F., Siegenthaler, U. and coauthors 1996. An efficient and accurate representation of complex oceanic and biospheric models of anthropogenic carbon uptake. Tellus 48B, 397-417.

Joshi, M. M., Shine, K. P., Ponater, M ., Stuber, N., Sausen, R. and coauthor 2003. A comparison of climate response to different radiative forcings in three general circulation models: towards an improved metric of climate change. Clim. Dynam. 20, 843-854.

Jourdain, L. and Hauglustaine, D. A. 2001. The global distribution of lightning NOx simulated on-line in a general circulation model. Phys. Chem. Earth $(C)$ 26, 585-591.

Kraabøl, A. G., Stordal, F., Berntsen, T. and Sundet, J. 2002. Impacts of NOx emissions from subsonic aircraft in a global 3-D CTM including plume processes. J. Geophys. Res. 107, doi:10.1029/2001JD001019.

Lacis, A. A., Wuebbles, D. J. and Logan, J. A. 1990. Radiative forcing of climate by changes in the vertical distribution of ozone. J. Geophys. Res. 95, 9971-9981.

Li, D. and Shine, K. P. 1995. A 4-Dimensional Ozone Climatology for UGAMP Models. UGAMP Internal Report 35. University of Reading, Reading.

Lin, X., Trainer, M. and Liu, S.C. 1988. On the non-linearity of the tropospheric ozone production. J. Geophys. Res. 93, 15 879-15888.

Mickley, L. J., Jacob, D. J., Field, B. D. and Rind, D. 2004. Climate response to the increase in tropospheric ozone since preindustrial times: a comparison between ozone and equivalent $\mathrm{CO}_{2}$ forcings. J. Geophys. Res. 109, D05106, doi:10.1029/2003JD003653.

Poppe, D., Wallasch, M. and Zimmermann, J. 1993. The dependence of the concentrations of $\mathrm{OH}$ on its precursors under moderately polluted conditions: a model study. J. Atmos. Chem. 16, 61-78.

Prather, M. J. 1996. Natural modes and timescales in atmospheric chemistry: theory, GWPs for $\mathrm{CH}_{4}$ and $\mathrm{CO}$, and runaway growth. Geophys. Res. Lett. 23, 2597-2600.

Prather, M. J., Gauss, M., Berntsen, T., Isaksen, I., Sundet, J. and coauthors 2003. Fresh air in the 21st century? Geophys. Res. Lett. 30(2), 1100, doi:10.1029/2002GL016285.

Price, C. and Rind, D. 1993. What determines the cloud-to-ground fraction in thunderstorms. Geophys. Res. Lett. 20, 463-466.

Prinn, R. G., Huang, J., Weiss, R. F., Cunnold, D. M., Fraser, P. J. and co-authors 2001. Evidence for substantial variations of atmospheric hydroxyl radicals in the past two decades. Science 292, 1882-1888.
Rogers, H., Teyssedre, H., Pitari, G., Grewe, V., van Veltoven, P. and Sundet, J. 2002. Model intercomparison of the transport of aircraftlike emissions from sub- and supersonic aircraft. Meteorol. Z. 11, 151-161.

Rotstayn, L. D. and Penner, J. E. 2001. Indirect aerosol forcing, quasiforcing and climate response. J. Climate 20, 2960-2975.

Sadourny, R. and Laval, K. 1984. January and July performance of the LMD general circulation model. In: New Perspectives in Climate Modeling (eds A. Berger and C. Nicolis), Elsevier, Amsterdam, 173197.

Sausen, R., Ponater, M., Stuber, N., Joshi, M., Shine, K. P. and coauthor 2002. Climate response to inhomogeneously distributed forcing agents. Proceedings of the Third International Symposium on non$\mathrm{CO}_{2}$ Greenhouse Gases. Mill Press, Rotterdam, 377-381.

Shine, K. P., Fuglestvedt, J. S., Stuber, N. and Hailemariam, K. 2005. Alternatives to the global warming potential for comparing climate impacts of emissions of greenhouse gases. Climatic Change 68, 281302.

Stevenson, D. S., Doherty, R. M., Sanderson, M., Collins, W. J., Johnson, C.E. and co-author 2004. Radiative forcing from aircraft NOx emissions: mechanisms and seasonal dependence. J. Geophys. Res. 109, doi:10.1029/2004JD004759.

Stuber, N., Ponater, M. and Sausen R. 2001. Is the climate sensitivity to ozone perturbations enhanced by stratospheric water vapor feedback? Geophys. Res. Lett. 28, 2887-2890.

Stuber, N., Ponater, M. and Sausen R. 2005. Why radiative forcing might fail as a predictor of climate change. Clim. Dynam. 24, 497-510.

Sundet, J. K. 1997. Model Studies with a 3-D Global CTM using ECMWF Data. PhD thesis, Department of Geophysics, University of Oslo.

Tiedtke, M. 1989. A comprehensive mass flux scheme for cumulus parameterization in large scale models. Mon. Weather Rev. 117, 17791800.

Van Leer, B. 1977. Towards ultimate conservative difference scheme, Part IV: A new approach to numerical convection. J. Comput. Phys. 23, 276-299.

Wang, W.-C., Dudek, M. P. and Liang, X.-Z. 1992. Inadequacy of effective $\mathrm{CO}_{2}$ as a proxy in assessing the regional climate change due to other radiatively active gases. Geophys. Res. Lett. 19, 1375-1378.

Wang, W.-C., Dudek, M. P., Liang, X.-Z. and Kiehl, J. T. 1991. Inadequacy of effective $\mathrm{CO}_{2}$ as a proxy in simulating the greenhouse effect of the other radiatively active gases. Nature 350, 573-577.

Wang, W.-C. and Sze, N. D. 1980. Coupled effects of atmospheric $\mathrm{N}_{2} \mathrm{O}$ and $\mathrm{O}_{3}$ on Earth's climate. Nature 286, 589-590.

Wild, O. and Prather, M. J. 2000. Excitation of the primary tropospheric chemical mode in a global three-dimensional model. J. Geophys. Res. 105, 24 647-24660.

Wild, O., Prather, M. J. and Akimoto, H. 2001. Indirect long-term global radiative cooling from NOx emissions. Geophys. Res. Lett. 28, 17191722 .

Wild, O., Zhu, X. and Prather, M. J. 2000. Fast-J: accurate simulation of in- and below cloud photolysis in tropospheric chemical models. $J$. Atmos. Chem. 37, 245-282.

Wuebbles, D. J. 1996. Three-dimensional chemistry in the greenhousean editorial comment. Climatic Change 34, 397-404. 